Human Mutation

\title{
Whole Genome Sequencing in patients with ciliopathies uncovers a novel recurrent tandem duplication in IFT140
}

\begin{tabular}{|c|c|}
\hline Journal: & Human Mutation \\
\hline Manuscript ID & humu-2018-0045 \\
\hline Wiley - Manuscript type: & Research Article \\
\hline Date Submitted by the Author: & 29-Jan-2018 \\
\hline Complete List of Authors: & $\begin{array}{l}\text { geoffroy, veronique; Laboratoire de Génétique Médicale, Institut de } \\
\text { Génétique Médicale d'Alsace, INSERM U1112, Fédération de Médecine } \\
\text { Translationnelle de Strasbourg (FMTS), Université de Strasbourg } \\
\text { Stoetzel, Corinne; UMR_S INSERM U1112, IGMA, Laboratoire de Génétique } \\
\text { médicale, } \\
\text { Scheidecker, Sophie; UMR_S INSERM U1112, IGMA, Laboratoire de } \\
\text { Génétique médicale, } \\
\text { SCHAEFER, Elise; Hôpital de Hautepierre, GENETICS } \\
\text { PERRAULT, Isabelle; INSERM U781, GENETICS } \\
\text { Bär, Séverine; Department of Molecular and Cellular Genetics, UMR7156, } \\
\text { Centre National de Recherche Scientifique (CNRS), Université de } \\
\text { Strasbourg, Strasbourg, France } \\
\text { Kröll, Ariane; UMR_S INSERM U1112, IGMA, Laboratoire de Génétique } \\
\text { médicale, } \\
\text { Delbarre, Marion; Hôpitaux universitaire de Strasbourg, Laboratoires de } \\
\text { diagnostic génétique } \\
\text { Antin, Manuela; Nouvel Hopital Civi, Laboratoire de Diagnostic Génétique } \\
\text { Jaeger, Anne-Sophie; Hôpitaux universitaire de Strasbourg, Laboratoires } \\
\text { de diagnostic génétique } \\
\text { Henry, Charline; Inserm U1163-institut Imagine } \\
\text { Blanché, Hélène; Fondation Jean-Dausset-Centre d'Etude du } \\
\text { Polymorphisme Humain (CEPH), Institut de Génétique Moléculaire, } \\
\text { Decker, Eva; Bioscentia, } \\
\text { Kloth, Katja; Institut für Humangenetik, Universitätsklinikum Hamburg- } \\
\text { Eppendorf, Hamburg, Germany } \\
\text { Klaus, Günter; University Marburg, KfH-Nierenzentrum für Kinder und } \\
\text { Jugendliche, Marburg, Germany } \\
\text { Mache, Christopher; Graz, } \\
\text { Martin-Coignard, dominique; CH le Mans, Service de Génétique Médicale } \\
\text { McGinn, Steven; CNRGH, Institut de Biologie François Jacob, DRF, CEA, } \\
\text { Evry, France } \\
\text { Boland, Anne; CNG } \\
\text { Deleuze, Jean-François; CNG } \\
\text { Friant, Sylvie; Department of Molecular and Cellular Genetics, UMR7156, } \\
\text { Centre National de Recherche Scientifique (CNRS), Université de } \\
\text { Strasbourg, Strasbourg, France } \\
\text { SAUNIER, Sophie; Université René Descartes, ; INSERM U-574, Hopital } \\
\text { Necker, Enfants Malades }\end{array}$ \\
\hline
\end{tabular}


ROZET, Jean-Michel; INSERM U781, GENETICS

Bergmann, Carsten; Aachen University, Department of Human Genetics Dollfus, Helene; UMR_S INSERM U1112, IGMA, Laboratoire de Génétique médicale,

Muller, Jean; Hôpitaux universitaire de Strasbourg, Laboratoires de diagnostic génétique; Laboratoire de Génétique Médicale, Institut de Génétique Médicale d'Alsace, INSERM U1112, Fédération de Médecine Translationnelle de Strasbourg (FMTS), Université de Strasbourg,

Mainzer-Saldino syndrome, IFT140, Structural variation, tandem

Key Words: duplication, whole-genome sequencing, Alu-mediated recombination, copy number variation

\section{SCHOLARONE}

Manuscripts 


\section{Whole Genome Sequencing in patients with ciliopathies}

\section{uncovers a novel recurrent tandem duplication in IFT140}

Véronique Geoffroy $^{1, *}$, Corinne Stoetzel ${ }^{1, *}$, Sophie Scheidecker ${ }^{1,2}$, Elise Schaefer ${ }^{1,3}$, Isabelle Perrault ${ }^{4}$, Séverine Bär ${ }^{5}$, Ariane Kröll ${ }^{1}$, Marion Delbarre ${ }^{2}$, Manuela Antin ${ }^{2}$, Anne-Sophie Leuvrey $^{2}$, Charline Henry ${ }^{6}$, Hélène Blanché ${ }^{7}$, Eva Decker ${ }^{8}$, Katja Kloth ${ }^{9}$, Günter Klaus ${ }^{10}$, Christoph Mache ${ }^{11}$, Dominique Martin-Coignard ${ }^{12}$, Steven McGinn ${ }^{13}$, Anne Boland ${ }^{13}$, JeanFrançois Deleuze ${ }^{7,13}$, Sylvie Friant ${ }^{5}$, Sophie Saunier ${ }^{6}$, Jean-Michel Rozet ${ }^{4}$, Carsten Bergmann $^{8,14}$, Hélène Dollfus ${ }^{1,15}$, Jean Muller ${ }^{1,2}$

${ }^{1}$ Laboratoire de Génétique médicale, UMR_S INSERM U1112, IGMA, Faculté de Médecine FMTS, Université de Strasbourg, Strasbourg, France

${ }^{2}$ Laboratoires de Diagnostic Génétique, Hôpitaux Universitaires de Strasbourg, Strasbourg Cedex, France

${ }^{3}$ Service de Génétique Médicale, Hôpitaux Universitaires de Strasbourg, Strasbourg, France.

${ }^{4}$ Laboratory of Genetics in Ophthalmology (LGO), INSERM UMR1163, Institute of Genetic Diseases, Imagine, Paris Descartes University, 75015 Paris, France.

${ }^{5}$ Department of Molecular and Cellular Genetics, UMR7156, Centre National de Recherche Scientifique (CNRS), Université de Strasbourg, Strasbourg, France.

${ }^{6}$ INSERM, U983, Paris Descartes University, Paris, France

${ }^{7}$ Centre d'études du polymorphisme humain-Fondation Jean Dausset, Paris, France

${ }^{8}$ Center for Human Genetics, Bioscientia, Ingelheim, Germany

${ }^{9}$ Institut für Humangenetik, Universitätsklinikum Hamburg-Eppendorf, Hamburg, Germany

${ }^{10}$ University Marburg, KfH-Nierenzentrum für Kinder und Jugendliche, Marburg, Germany

${ }^{11}$ Department of Pediatrics, Medical University of Graz, Graz, Austria. 
${ }^{12}$ Service de Génétique, Centre Hospitalier, CCLAD, Le Mans, France

${ }^{13} \mathrm{CNRGH}$, Institut de Biologie François Jacob, DRF, CEA, Evry, France

${ }^{14}$ Department of Medicine, University Hospital Freiburg, Freiburg, Germany

${ }^{15}$ Centre de Référence pour les affections rares en génétique ophtalmologique, CARGO,

Filière SENSGENE, Hôpitaux Universitaires de Strasbourg, 67091 Strasbourg, France.

*equal contributor

Corresponding Author: Jean Muller

Email address: jeanmuller@unistra.fr 


\begin{abstract}
Ciliopathies represent a wide spectrum of rare diseases with overlapping phenotypes and a high genetic heterogeneity. Among those, IFT140 is implicated in a variety of phenotypes ranging from isolated retinis pigmentosa to more syndromic cases such as the Bardet-Biedl syndrome. Using whole genome sequencing in patients with uncharacterized ciliopathies, we identified a novel recurrent tandem duplication of exon 27 to $30(6.7 \mathrm{~kb})$ in IFT140, c.3454488_4182+2588dup p.(Tyr1152_Thr1394dup), missed by whole exome sequencing. Pathogenicity of the mutation was assessed on the patients' skin fibroblasts. Several hundreds of patients with a ciliopathy phenotype were screened and biallelic mutations were identified in 11 families representing 12 pathogenic variants of which 7 are novel. Among those unrelated families especially with a Mainzer-Saldino syndrome, 8 carried the same tandem duplication ( 2 at the homozygous state and 6 at the heterozygous state).

In conclusion, we demonstrated the implication of structural variations in IFT140 related diseases expanding its mutation spectrum. We also provide evidences for a unique genomic event mediated by an Alu-Alu recombination occurring on a shared haplotype. We confirm that whole genome sequencing can be instrumental in the ability to detect structural variants for genomic disorders.
\end{abstract}

Keywords: IFT140, Mainzer-Saldino syndrome, structural variation, copy number variation, tandem duplication, Alu-mediated recombination, whole-genome sequencing. 


\section{Background}

Mainzer-Saldino syndrome (MSS, MIM 266920) is a rare $(<1 / 1,000,000)$ autosomal recessive ciliopathy characterized by severe early-onset retinal dystrophy, phalangeal coneshaped epiphyses, chronic renal failure, and mild radiographic abnormality of the proximal femur (Perrault, et al., 2012), known to be caused by IFT140 (Khan, et al., 2014; Perrault, et al., 2012; Schmidts, et al., 2013) and IFT172 mutations (Halbritter, et al., 2013). Both genes have been implicated in several other ciliopathies ranging from isolated Retinis Pigmentosa (RP) to more syndromic cases such as Jeune or Bardet-Biedl syndromes (Bifari, et al., 2016; Bujakowska, et al., 2015; Schaefer, et al., 2016).

Intraflagellar transport (IFT) genes are involved in a bidirectional (anterograde and retrograde) transport process essential for the assembly and the maintenance of the cilia through the redistribution of ciliary proteins between the cell body and the cilium. In particular, IFT140 a component of the IFT complex A (IFT-A) responsible of the retrograde IFT, is vital for both the development and the maintenance of outer segments of photoreceptors and has a specific role in opsin transport across the connecting cilium (Blacque, et al., 2006; Crouse, et al., 2014) of the photoreceptors. Previously, 46 different mutations in 56 families have been reported in IFT140 (Additional File 1: Table S1), encompassing missenses, essential splice sites, stop and frameshifts mutations but no structural variations (SV) such as copy number variant (CNV). Interestingly, 10 mono allelic variants cases have also been reported with no second pathogenic allele detected to date (Additional File 1: Table S1).

In this study, we report for the first time a structural variation (tandem duplication) in IFT140 identified by Whole Genome Sequencing (WGS) and missed by Whole Exome Sequencing (WES). The impact of this mutation was further assessed in patients' skin fibroblasts. Given 
the difficulty to identify this mutation and the genomic context surrounding the breakpoints, we speculated that it might have been missed by other genetic screenings and that several other families might carry this mutation. We finally report 8 unrelated families carrying the mutation either at the homozygous or the heterozygous state, out of 11 families identified with IFT140 biallelic mutations in total. Moreover, the characterization of the breakpoints allowed to delineate a potential molecular mechanism and to design a specific duplex PCR that will help screening further patients (including our cohorts).

\section{Materials and Methods}

\section{Subjects}

Study protocols used in each cohort have been approved by the corresponding Institutional Review Board or equivalent committees (as an example in Strasbourg, "Comité Protection des Personnes" EST IV, NDC-20142222), and written informed consent was given from each participant or parents. Our research complies with the Declaration of Helsinki. Written informed consent for open-access publication was provided by the participants or their parents. DNA of additional affected and unaffected family members was requested whenever it was considered informative. Skin fibroblasts were obtained for family A. Clinical data for all 11 families are presented in Additional File 1: Table S2.

\section{Whole Genome Sequencing}

WGS was performed for the two affected siblings from family A (A-II.1 and A-II.2) and their parents (A-I.1 and A-I.2) by the Centre National de Génotypage (Institut de Génomique, CEA). Genomic DNA was used to prepare a library for whole genome sequencing, using the Illumina TruSeq DNA PCR-Free Library Preparation Kit, according to the manufacturer's 
instructions. After normalization and quality control, qualified libraries have been sequenced on a HiSeq2000 platform from Illumina (Illumina Inc., CA, USA), as paired-end $100 \mathrm{bp}$ reads. At least 3 lanes of HiSeq2000 flow cell have been produced for each sample, in order to reach an average sequencing depth of 30x for each sample. Sequence quality parameters have been assessed throughout the sequencing run and standard bioinformatics analysis of sequencing data was based on the Illumina pipeline to generate FASTQ file for each sample. The sequence reads were aligned to the reference sequence of the human genome (GRCh37) using the Burrows-Wheeler Aligner (BWA V7.12) ( $\mathrm{Li}$ and Durbin, 2010). The UnifiedGenotyper and HaplotypeCaller modules of the Genome Analysis ToolKit (GATK) (DePristo, et al., 2011), Platypus (http://www.well.ox.ac.uk/platypus) and Samtools (Li, et al., 2009) were used for calling both single nucleotide variations (SNV) and small insertion/deletion (indel).

\section{Bioinformatics analysis}

Annotation and ranking of SNV and indel were performed by VaRank (Geoffroy, et al., 2015) in combination with the Alamut Batch software (Interactive Biosoftware, Rouen, France). Very stringent filtering criteria were used for excluding non-pathogenic variants, in particular: (1) variants represented with an allele frequency of more than $1 \%$ in public variation databases either dbSNP 138 (Sherry, et al., 2001), the Exome Variant Server (NHLBI GO Exome Sequencing Project, http://evs.gs.washington.edu/EVS/), the 1000Genomes (Genomes Project, et al., 2015), the ExAC browser database(Lek, et al., 2016) or our internal exome database, (2) variants in 5' UTR, 3' UTR, downstream, upstream or intronic locations without pathogenic prediction of local splice effect, and (3) synonymous variants without prediction of local splice effect. Variant effect on the nearest splice site was predicted using MaxEntScan (Yeo and Burge, 2004), NNSplice (Reese, et al., 1997) and Splice Site Finder (Shapiro and 
Senapathy, 1987). Our analysis was focused on compound heterozygous and homozygous variants $(\mathrm{SNV} / \mathrm{indel} / \mathrm{SV})$ consistent with a recessive mode of transmission. Structural variants were predicted using by default the CANOES program (Backenroth, et al., 2014) and annotated thanks to our in house script AnnotSV (manuscript in preparation, http://www.lbgi.fr/AnnotSV/) based on the classical annotations such as the Database of Genomic Variants (DGV) (MacDonald, et al., 2014). The IFT140 nomenclature is based on the accession number NM_014714.3 from the RefSeq database (O'Leary, et al., 2016). Genomic coordinates are defined according to GRCh37/hg19 assembly downloaded from the University of California Santa Cruz (UCSC) genome browser (Tyner, et al., 2017).

\section{Sanger validation and segregation}

Sanger sequencing was performed by PCR amplification with $50 \mathrm{ng}$ of genomic DNA template. The primers were designed with Primer 3 (http://frodo.wi.mit.edu/primer3) and are detailed in Additional File 1: Table S3. Bidirectional sequencing of the purified PCR products was performed by GATC Sequencing Facilities (Konstanz, Germany).

\section{qPCR quantification}

Absolute quantification was performed using the SyberGreen Mastermix Quantitect (Qiagen) measured on the LightCycler 480 (Roche). Amplicons were designed in exon 30 of IFT140 and compared to two reference genes $(H B B$ and $H M B S)$. Each samples have been done in duplicate and standard deviation was $<0.2$. Standard curve have been established using 5 different DNA quantity (50ng, 25ng, 10ng, 5ng and 1ng) and PCR efficiency was assessed for each amplicon $(1.9<\mathrm{PCR}$ efficiency<2.0). Ratio between the mean concentrations from the amplicon of interest compared to reference gene was collected. The mean values for both 
control genes was calculated for each patient and plotted. The primers were designed with Primer 3 and are detailed in Additional File 1: Table S3

\section{RNA analysis}

RNA was extracted from skin fibroblasts of individual II.1 and a healthy unrelated control using Rneasy RNA kit (Qiagen) then we performed reverse transcription using the iScriptTM cDNA Synthesis Kit (BioRad, Hercules, CA).

\section{Cell culture}

Fibroblasts of patients and control individuals were obtained by skin biopsy as previously described (Scheidecker, et al., 2014). To induce primary cilium formation, cells were deprived of serum by growth for $24 \mathrm{hrs}$ in DMEM with 1\% PSG but only $0.1 \%$ FCS (conditions -FCS) as previously described (Stoetzel, et al., 2016).

\section{Immunofluorescence}

Primary fibroblasts from patients and control individuals were grown in Nunc Lab-Tek chamber slides (Thermo Scientific) and ciliogenesis was done as described above. Primary cilia were labelled with an antibody directed against acetylated a-tubulin highlighting the axoneme41. Pictures were taken either on a fluorescence microscope (Figure 2A) or a confocal microscope (Figure 2C). Primary and secondary antibodies used in this study as well as their dilution are indicated in Additional File 1: Table S4.

\section{Cohort screening}

A duplex PCR was designed to specifically detect the tandem duplication. Primers and example conditions are provided in Additional File 1: Table S3 and Figure S1. Additional 
targeted exome sequencing datasets have been reanalyzed (see Additional File 1: supplementary Methods).

\section{Alu pair analysis}

We obtained the annotations and sequences for the two Alu repeat in the duplication junction region from the RepeatMasker track of the UCSC genome browser (Tyner, et al., 2017). We subsequently aligned the Alu sequences and computed the identity using the online tool EMBOSS Matcher (Rice, et al., 2000).

\section{Results}

\section{Identification of biallelic mutations in IFT140}

Two affected individuals born from healthy non consanguineous parents (family A, Figure 1A), named II.1 and II.2, were referred to our lab with retinitis pigmentosa, short stature $(152 \mathrm{~cm}$ and $158 \mathrm{~cm}$ respectively at 16 and $15 \mathrm{yo})$, brachydactyly, moderate renal failure and overweight for II.1 (Additional File 1: Table S2). This Bardet-Biedl like phenotype prompted us to perform an extensive first genetic analysis including Sanger sequencing of recurrent BBS mutations (Muller, et al., 2010), targeted exome sequencing (Redin, et al., 2012) and WES without success. Indeed no biallelic mutations including copy number variant could be identified (see Additional File 1: Table S5). Hence, considering that affected individuals from family A may harbor mutations in a region not (well) covered by the WES (i.e. deep intronic, promotor...), we applied WGS to the 2 affected individuals and their parents. A combined analysis including both SNV/indel and structural variant revealed biallelic mutations in IFT140, a gene known to be responsible of several ciliopathies (ranging from isolated RP to more syndromic cases such as Jeune or Mainzer-Saldino syndromes) compatible with the phenotype of the affected patients. 
First, the two affected individuals were found heterozygous for a possible splice mutation in intron 20 , c. $2577+25 \mathrm{G}>\mathrm{A}$, predicted to have a local splice effect as a new strong donor site. This variant was reported previously and is not present in any variation database (e.g. ExAC or 1000G). Co-segregation analysis revealed the paternal inheritance (Figure 1A, primers used are detailed in Additional File 1: Table S3). Patient's RNA analysis confirmed that a novel donor splice site within the intron 20 resulted in the incorporation of 21 additional bp (r.2577_2578insGTGAGGGGCGCCCGCCATGGG) that are predicted to add 7 new amino acids to the protein sequence (p.Leu859_Glu860insValArgGlyAlaArgHisGly) (Figure 1B).

Second, in trans to this mutation, structural variant analysis revealed a maternally inherited (Figure 1A) duplication of exons 27 to 30 (of sizes $6.7 \mathrm{~kb}$ ). Analysis of the mapped reads revealed that the duplication is occurring in tandem in direct orientation within the gene (Additional File 1: Figure S2) with breakpoints located in intron 26 and intron 30. This tandem duplication has not been reported previously in patients and is not present in DGV. The results were confirmed by qPCR (Figure 1C) delineating the expected maternal inheritance. The duplication is predicted to be in frame and to add 243 amino acids within the tetratricopeptide repeat (TPR) domain of the IFT140 protein (c.3454-488_4182+2588dup, p.Tyr1152_Thr1394dup). RNA analysis revealed that the duplicated exons are transcribed (Figure 1D). Western blot analysis revealed only a single band of the approximate size of the wild type protein suggesting that the allele carrying the duplication is not detected as a protein (Figure 1E).

Immunofluorescence analysis in patients fibroblasts revealed that IFT140 is mislocalized compared to sex/age matched control cells. Indeed, when grown in ciliary conditions, patient skin fibroblasts developed primary cilia less often (Figure 2A). Thus while $75 \%$ of control cells developed a primary cilium, only about $50-55 \%$ of patient cells did so (Figure 2 B). It is to notice that primary cilia did not seem to be altered since when cells were deprived of 
serum, fixed for immunofluorescence and labeled with an anti-acetylated tubulin antibody, their cilium as observed by fluorescence microscope and measured with image $\mathrm{J}$ (Schneider, et al., 2012) was about 2-2,5 $\mu \mathrm{m}$ both in control and patient cells (Figure 2B). Nevertheless, a difference in organisation could be noticed when co-labelling was performed with an antiIFT140 antibodies (Figure 2C). Then, localisation of IFT140 at the base of the cilium could be observed using confocal microscopy in $82 \%$ of ciliated control cells but only in about $14 \%$ of ciliated patient fibroblasts (Figure 2D). Thus, the mutations found in the patients lead to a significant decrease of cilium formation and a loss of IFT140 localisation at the base of the cilium.

\section{Mutation screening in a large cohort}

To explore additional cases of this duplication possibly missed by prior analysis, we retrospectively screened our cohorts and reanalyzed available high throughput sequencing panels including the IFT140 gene. As mutations in IFT140 are known to cause isolated to syndromic retinal degeneration (Bifari, et al., 2016), this included 126 patients using the Leber panel of the Imagine institute, 117 patients using the RP panel of Strasbourg Hospital, and 104 patients using the Ciliome panel of the Imagine institute (see Methods and Additional File 1: methods online). We also setup a duplex PCR around the breakpoints (Additional File 1: Figure S1) and screened all our negative cases, including 207 from our Bardet-Biedl cohort, 150 isolated RP and 40 IFT140 heterozygous patients. All together we identified 11 additional families positive for biallelic mutations in IFT140 (Figure 3 and Additional File 1: Table S1) among which 10 families have a phenotype compatible with a Mainzer Saldino syndrome and one patient presents with isolated retinitis pigmentosa. Among the MSS patients, three patients presented a phenotype overlapping with another ciliopathy: two with Jeune syndrome and one with Sensenbrenner syndrome. Eight of the 11 families carried the exact same tandem duplication either at the heterozygous state ( 3 copies) or at the 
homozygous state (4 copies) (Figure 3A, Additional File 1: Figure S3). Among the novel mutations identified, we observed 2 missenses at the heterozygous state c.1319T $>\mathrm{C}$ (p.Leu440Pro), c.2177C > T (p.Pro726Leu) that are both predicted deleterious (Additional File 1: supplementary Methods). Among the novel mutations we also identified another CNV, a large deletion encompassing exon 27 to 29 (c.3454-1005_4040+737delinsCCC, Additional File 1: Figure S4) that does not share the same breakpoints compared to the tandem duplication. Thus to date, 120 pathogenic alleles have been reported for IFT140 of which the tandem duplication represents 10 alleles. Interestingly this tandem duplication is the second most frequent mutation for IFT140-affected patients.

\section{Founder effect or recurrent mechanism?}

Given the relatively high frequency (8/65 families) of this duplication in the patients described with IFT140 mutations, we performed 3 additional explorations to assess whether the duplication was an independent recurrent mechanism or the same mutational event derived from a common ancestry suggesting a founder effect. First, we screened a French cohort of 354 WGS of healthy individuals (FREX dataset), for which CNV analysis (CANOES) as well as visual inspections of the bam files (IGV batch scripting (Thorvaldsdottir, et al., 2013)) did not reveal any corresponding allele, as expected due to the IFT140 diseases prevalence (e.g. MSS: 1/1,000,000). Second, we compared the haplotype at the IFT140 locus from the different patients for which NGS data was available. In total 15 haplotypes, including 6 carrying the duplication, from 3 different families, were analyzed (see Additional File 1: Table S6). We observed a shared haplotype between the duplication carriers at the IFT140 locus, suggesting a founder effect. Third, we characterized the genomic localization around the breakpoint junctions. Sanger sequencing confirmed the breakpoint's coordinates (Figure 1A and Additional File 1: Figure S2) and demonstrated that the exact same breakpoint is shared among all patients tested (Family C was not investigated). The 
breakpoints overlapped two distinct repeated elements from the Alu family, AluJb and AluJr (Figure 4A). Pairwise alignment of the two Alu sequences (Additional File 1: Figure S5) revealed a conservation of $68 \%$ of identity that reached $81 \%$ in the junction region (Figure 4B). The tandem duplication is resulting in an Alu hybrid (Figure 4C) at both sides. Alu-Alu recombination is a prominent mechanism underlying the formation of pathogenic $\mathrm{SV}$ associated with distinct diseases (Boone, et al., 2014; Stankiewicz, et al., 2009). Altogether, this led us to speculate that this tandem duplication is a rare event, which arises from a common ancestor due to an $A l u$-Alu mediated genomic recombination.

\section{Discussion}

The advent of next generation sequencing, especially Whole Exome Sequencing (WES), in the past 10 years was a tremendous step that led to the identification of many mutations accelerating the discovery of novel genes involved in human genetic diseases (Chong, et al., 2015). Nevertheless, the diagnostic yield of WES is plateauing between $25 \%$ to $50 \%$ depending on the disease (Chong, et al., 2015; Taylor, et al., 2015) leaving many patients still with no molecular diagnosis. The use of RNA sequencing has recently extended the percentage by $10 \%$ to $66 \%$ (depending on the context: with or without a strong candidate by prior DNA sequencing) by helping identifying unseen defects or interpreting variations found in the WES (Cummings, et al., 2017; Kremer, et al., 2017). Lastly, Whole Genome Sequencing (WGS) of human patients has proven to be an instrumental tool for identifying the whole spectrum of genetic anomalies (Gilissen, et al., 2014) and will replace in a close future other genetic screening.

In line with this, we applied a range of genetic screening including targeted sequencing, WES and then finally WGS to unsolved patients affected with a ciliopathy. The combination of 
WGS and CNV analysis was able to uncover a tandem duplication unseen by the WES and to reconsider a distant splice site mutation.

Interestingly, the tandem duplication could be identified in family A only by using the WGS and not the WES data. Indeed, CANOES failed to identify the event in one of the individuals (Additional File 1: Table S7), which prevented us from considering this as a mutation of interest but made us rather discard it as a false positive of the method. Thereupon, it is well known that $\mathrm{CNV}$ detection from next generation sequencing (NGS) datasets is feasible and many publication reported positive results either on gene panels or WES (de Ligt, et al., 2013; Redin, et al., 2012). However, this remains challenging (Tan, et al., 2014). WGS provides a much more uniform distribution of sequencing-quality parameters and by nature does not have the restriction of noncontiguous regions of interests (captured exons). Therefore, it is more suited for SV identification (Belkadi, et al., 2015). Having that in mind, we further tested the CNV detection using 2 other popular programs (see Additional File 1: Table S7) which failed to detect the tandem duplication in family A patients (Additional File 1: Table S7). These results confirmed many efforts are still required to ensure a high quality CNV detection from NGS data, even with the large number of programs and methods available. Nevertheless, thanks to the split reads from WGS data, once a CNV is detected one can easily define the CNV breakpoints and further characterize the mechanism, as done in this study (Additional File 1: Figure S2).

Analysis of the breakpoint positions and in particular the split reads allowed us to identify overlapping Alu elements at the breakpoint junction. Alignment of the Alu regions surrounding the junction revealed that both elements share $81 \%$ identity and exhibit a microhomology region of 6 nucleotides. Because the recombination occurred between homologous sequences (e.g. imperfect match substrates), it is most likely mediated by mechanisms other than nonallelic homologous recombination, which are mostly recurrent 
events (NAHR, for review see (Carvalho and Lupski, 2016)). Among the possible molecular mechanisms, that include non-homologous end joining (NHEJ) and replication-based mechanisms such as break-induced replication (BIR), microhomology-mediated BIR (MMBIR), serial replication slippage (SRS) and fork stalling and template switching (FoSTeS), we believe that the presence of a microhomology region points most likely to a MMBIR driven recombination. Given the nonrecurrent nature of those mechanisms, the common haplotype and the exact same breakpoint junction observed in most of our patients, we hypothesized that the genomic event that gave rise to this tandem duplication occurred once on a common IFT140 haplotype.

IFT140 is a 1462-amino-acid protein encoded by 31 exons and composed of 5 WD repeats and 9 tetratricopeptide repeats (TPR) both known to act as protein-protein interaction domains that might be involved in IFT140 interactions within the IFT-A complex (Zhu, et al., 2017). To date, 45 different pathogenic alleles have already been described throughout the IFT140 gene with no clustering or domain preference (Figure 4A). Most of them are private mutations but several are found multiple times like the c.634G $>$ A (p.Gly212Arg) (7 alleles) which has been proven to affect the splicing of exon 6 (Helm, et al., 2017) or the c.2399+1G $>$ T (5 alleles) (Additional File 1: Table S1). The most frequent mutation (31 alleles) is a missense (c.1990G>A, p.Glu664Lys) that has been observed in multiple studies and especially in 11 consanguineous families from the Arabian Peninsula sharing a common ancestor (Bifari, et al., 2016) which might bias the allele count. Nevertheless, the tandem duplication described in our study is the second most frequent cause of mutation in IFT140 representing 10 alleles.

In family A, the two mutations identified required extensive and careful analysis to be considered. One mutation was predicted to affect the splicing of exon 20 (c. $2577+25 \mathrm{G}>\mathrm{A})$ which was confirmed at the RNA level (r.2577_2578insGTGAGGGGCGCCCGCCATGGG), and suggested to add 7 amino acid to the protein sequence 
(p.Leu859_Glu860insValArgGlyAlaArgHisGly). The tandem duplication of exons 27 to 30 (c.3454-488_4182+2588dup, p.Tyr1152_Thr1394dup) is predicted to add 243 amino acids within the TPR repeat domain. Skin fibroblast analysis revealed RNA synthesis in the patient cells but no protein could be identified by Western Blot at the predicted size. We hypothesize that the protein was not stable enough to maintain its $3 \mathrm{D}$ structure. Functional analysis on the patients' cells further revealed a reduced level of ciliated cells and mislocalization of the IFT140 mutant away from the cilia base.

The Mainzer Saldino syndrome is a syndrome characterized by skeletal phenotype with phalangeal cone-shaped epiphyses, chronic renal disease, and retinal dystrophy. Overlapping phenotypes have been described with other skeletal ciliopathies such as the Jeune or Sensenbrenner syndrome. In our cohort the diagnosis of MSS was not made in all patients before the molecular analysis. However, all of them except one with an isolated retinitis pigmentosa, fulfilled the criteria for this diagnosis after a new careful clinical and radiological examination. Indeed, 11 patients presented digits anomalies, including 8 with phalangeal cone-shaped epiphyses. Nine patients developed renal failure among which 7 have a severe and early onset renal disease ( 1.5 years old to 23 years old) as previously described (Schmidts, et al., 2013). The retinal dystrophy is constantly reported with a highly variable age of onset. Among our cohort, a single patient presented an isolated retinitis pigmentosa (as previously reported by others (Hull, et al., 2016)). Two patients have thoracic dystrophy which is a clinical criteria of Jeune syndrome and one patient has a craniosynostosis compatible with a Sensenbrenner syndrome. These descriptions illustrate well the overlap existing between the different ciliopathies associated with mutation in IFT140. On a molecular level, no genotype-phenotype correlation could be established in our cohort, especially regarding the patients carrying the duplication at the homozygous or the heterozygous state. 


\section{Conclusions}

In summary, we report here 11 novel unrelated families with mutations in IFT140. Among them, 8 families carry a recurrent tandem duplication of 4 exons either at the heterozygous state or the homozygous state, for which we have assessed the pathogenicity in the pateints cells. This is the first time that a structural variation is reported in IFT140 expanding the mutation spectrum for this gene. Notably, this large duplication was missed by the WES analysis but uncoverd thanks to the whole genome, pointing out the power of such analysis.

\section{Availability of data and material}

Data generated or analyzed during this study are included in the published article and the corresponding supplementary data. The raw sequencing data generated in the course of this study are not publicly available due to the protocol and the corresponding consents used that did not include such information. All variants have been submitted to ClinVar (https://www.ncbi.nlm.nih.gov/clinvar/). Anonymised NGS data and genomic variant data files will be made available upon request from qualified investigators studying the molecular basis of genomic disorders. Datasets can be obtained via the corresponding author on reasonable request.

\section{Acknowledgements}

We would like to thank the patients and their family for their participation. We thank Daniel Backenroth and Olivier Quenez for their help in the bioinformatics setup of CANOES, Arnaud Kress and Antony Le Béchec for informatic support, Amélie Piton, Bénédicte Gérard and Ilia Humbert for scientific discussion. We also thank Emmanuelle Génin, Pierre Lindenbaum and Richard Redon for giving us access to the genome dataset from the FREX 
project and the Genomic and Bioinformatic Platform of Institut Imagine (Patrick Nitschké, and Cécile Masson).

\section{Disclosure Statment}

Eva Decker and Carsten Bergmann are employees of Bioscientia/Sonic Healthcare. Günter Klaus benefited from a travel grants from The Apheresis Research Institute Cologne, the DGFF (Die Deutsche Gesellschaft zur Bekämpfung von Fettstoffwechselstörungen und ihren Folgeerkrankungen) and is consultant to Vifor pharma, Switzerland concerning a pediatric phosphat binder trial.

\section{Funding Information}

The WGS research was supported by the Laboratory of Excellence GENMED (Medical Genomics) grant no. ANR-10-LABX-0013 managed by the National Research Agency (ANR) part of the Investment for the Future program. Whole exome sequencing was performed by the IGBMC Microarray and Sequencing platform, a member of the 'France Génomique' consortium (ANR-10-INBS-0009) and funded by "La Fondation Maladie Rare". The RP panel is supported by the French program PHRC I 2013 HUS N 5724 and by grants from the Retina France to IP, UNADEV- AVIESAN ITMO MNP to JMR. In addition, CB holds a part-time faculty appointment at the University of Freiburg. His research lab receives support from the Deutsche Forschungsgemeinschaft (DFG) Collaborative Research Centre (SFB) KIDGEM 1140 and the Federal Ministry of Education and Research (BMBF, 01GM1515C). 


\section{References}

Backenroth D, Homsy J, Murillo LR, Glessner J, Lin E, Brueckner M, Lifton R, Goldmuntz E, Chung WK, Shen Y. 2014. CANOES: detecting rare copy number variants from whole exome sequencing data. Nucleic Acids Res 42(12):e97.

Belkadi A, Bolze A, Itan Y, Cobat A, Vincent QB, Antipenko A, Shang L, Boisson B, Casanova JL, Abel L. 2015. Whole-genome sequencing is more powerful than whole-exome sequencing for detecting exome variants. Proc Natl Acad Sci U S A 112(17):5473-8.

Bifari IN, Elkhamary SM, Bolz HJ, Khan AO. 2016. The ophthalmic phenotype of IFT140related ciliopathy ranges from isolated to syndromic congenital retinal dystrophy. $\mathrm{Br} \mathrm{J}$ Ophthalmol 100(6):829-33.

Blacque OE, Li C, Inglis PN, Esmail MA, Ou G, Mah AK, Baillie DL, Scholey JM, Leroux MR. 2006. The WD repeat-containing protein IFTA-1 is required for retrograde intraflagellar transport. Mol Biol Cell 17(12):5053-62.

Boone PM, Yuan B, Campbell IM, Scull JC, Withers MA, Baggett BC, Beck CR, Shaw CJ, Stankiewicz P, Moretti P and others. 2014. The Alu-rich genomic architecture of SPAST predisposes to diverse and functionally distinct disease-associated $\mathrm{CNV}$ alleles. Am J Hum Genet 95(2):143-61.

Bujakowska KM, Zhang Q, Siemiatkowska AM, Liu Q, Place E, Falk MJ, Consugar M, Lancelot ME, Antonio A, Lonjou C and others. 2015. Mutations in IFT172 cause isolated retinal degeneration and Bardet-Biedl syndrome. Hum Mol Genet 24(1):230-42.

Carvalho CM, Lupski JR. 2016. Mechanisms underlying structural variant formation in genomic disorders. Nat Rev Genet 17(4):224-38.

Chong JX, Buckingham KJ, Jhangiani SN, Boehm C, Sobreira N, Smith JD, Harrell TM, McMillin MJ, Wiszniewski W, Gambin T and others. 2015. The Genetic Basis of Mendelian Phenotypes: Discoveries, Challenges, and Opportunities. Am J Hum Genet 97(2):199-215.

Crouse JA, Lopes VS, Sanagustin JT, Keady BT, Williams DS, Pazour GJ. 2014. Distinct functions for IFT140 and IFT20 in opsin transport. Cytoskeleton (Hoboken) 71(5):302-10.

Cummings BB, Marshall JL, Tukiainen T, Lek M, Donkervoort S, Foley AR, Bolduc V, Waddell LB, Sandaradura SA, O'Grady GL and others. 2017. Improving genetic diagnosis in Mendelian disease with transcriptome sequencing. Sci Transl Med 9(386).

de Ligt J, Boone PM, Pfundt R, Vissers LE, Richmond T, Geoghegan J, O'Moore K, de Leeuw N, Shaw C, Brunner HG and others. 2013. Detection of clinically relevant copy number variants with whole-exome sequencing. Hum Mutat 34(10):1439-48.

DePristo MA, Banks E, Poplin R, Garimella KV, Maguire JR, Hartl C, Philippakis AA, del Angel G, Rivas MA, Hanna M and others. 2011. A framework for variation discovery and genotyping using next-generation DNA sequencing data. Nat Genet 43(5):491-8.

Genomes Project C, Auton A, Brooks LD, Durbin RM, Garrison EP, Kang HM, Korbel JO, Marchini JL, McCarthy S, McVean GA and others. 2015. A global reference for human genetic variation. Nature 526(7571):68-74.

Geoffroy V, Pizot C, Redin C, Piton A, Vasli N, Stoetzel C, Blavier A, Laporte J, Muller J. 2015. VaRank: a simple and powerful tool for ranking genetic variants. PeerJ 3:e796.

Gilissen C, Hehir-Kwa JY, Thung DT, van de Vorst M, van Bon BW, Willemsen MH, Kwint M, Janssen IM, Hoischen A, Schenck A and others. 2014. Genome sequencing identifies major causes of severe intellectual disability. Nature 511(7509):344-7.

Halbritter J, Bizet AA, Schmidts M, Porath JD, Braun DA, Gee HY, McInerney-Leo AM, Krug P, Filhol E, Davis EE and others. 2013. Defects in the IFT-B component IFT172 cause Jeune and Mainzer-Saldino syndromes in humans. Am J Hum Genet 93(5):915-25. 
Helm BM, Willer JR, Sadeghpour A, Golzio C, Crouch E, Vergano SS, Katsanis N, Davis EE. 2017. Partial uniparental isodisomy of chromosome 16 unmasks a deleterious biallelic mutation in IFT140 that causes Mainzer-Saldino syndrome. Hum Genomics 11(1):16.

Hull S, Owen N, Islam F, Tracey-White D, Plagnol V, Holder GE, Michaelides M, Carss K, Raymond FL, Rozet JM and others. 2016. Nonsyndromic Retinal Dystrophy due to Bi-Allelic Mutations in the Ciliary Transport Gene IFT140. Invest Ophthalmol Vis Sci 57(3):1053-62.

Khan AO, Bolz HJ, Bergmann C. 2014. Early-onset severe retinal dystrophy as the initial presentation of IFT140-related skeletal ciliopathy. J AAPOS 18(2):203-5.

Kremer LS, Bader DM, Mertes C, Kopajtich R, Pichler G, Iuso A, Haack TB, Graf E, Schwarzmayr T, Terrile $\mathrm{C}$ and others. 2017. Genetic diagnosis of Mendelian disorders via RNA sequencing. Nat Commun 8:15824.

Lek M, Karczewski KJ, Minikel EV, Samocha KE, Banks E, Fennell T, O'Donnell-Luria AH, Ware JS, Hill AJ, Cummings BB and others. 2016. Analysis of protein-coding genetic variation in 60,706 humans. Nature 536(7616):285-91.

Li H, Durbin R. 2010. Fast and accurate long-read alignment with Burrows-Wheeler transform. Bioinformatics 26(5):589-95.

Li H, Handsaker B, Wysoker A, Fennell T, Ruan J, Homer N, Marth G, Abecasis G, Durbin R, Genome Project Data Processing S. 2009. The Sequence Alignment/Map format and SAMtools. Bioinformatics 25(16):2078-9.

MacDonald JR, Ziman R, Yuen RK, Feuk L, Scherer SW. 2014. The Database of Genomic Variants: a curated collection of structural variation in the human genome. Nucleic Acids Res 42(Database issue):D986-92.

Muller J, Stoetzel C, Vincent MC, Leitch CC, Laurier V, Danse JM, Helle S, Marion V, Bennouna-Greene V, Vicaire S and others. 2010. Identification of 28 novel mutations in the Bardet-Biedl syndrome genes: the burden of private mutations in an extensively heterogeneous disease. Hum Genet 127(5):583-93.

O'Leary NA, Wright MW, Brister JR, Ciufo S, Haddad D, McVeigh R, Rajput B, Robbertse B, Smith-White B, Ako-Adjei D and others. 2016. Reference sequence (RefSeq) database at NCBI: current status, taxonomic expansion, and functional annotation. Nucleic Acids Res 44(D1):D733-45.

Perrault I, Saunier S, Hanein S, Filhol E, Bizet AA, Collins F, Salih MA, Gerber S, Delphin N, Bigot K and others. 2012. Mainzer-Saldino syndrome is a ciliopathy caused by IFT140 mutations. Am J Hum Genet 90(5):864-70.

Redin C, Le Gras S, Mhamdi O, Geoffroy V, Stoetzel C, Vincent MC, Chiurazzi P, Lacombe D, Ouertani I, Petit F and others. 2012. Targeted high-throughput sequencing for diagnosis of genetically heterogeneous diseases: efficient mutation detection in Bardet-Biedl and Alstrom syndromes. J Med Genet 49(8):502-12.

Reese MG, Eeckman FH, Kulp D, Haussler D. 1997. Improved splice site detection in Genie. J Comput Biol 4(3):311-23.

Rice P, Longden I, Bleasby A. 2000. EMBOSS: the European Molecular Biology Open Software Suite. Trends Genet 16(6):276-7.

Schaefer E, Stoetzel C, Scheidecker S, Geoffroy V, Prasad MK, Redin C, Missotte I, Lacombe D, Mandel JL, Muller J and others. 2016. Identification of a novel mutation confirms the implication of IFT172 (BBS20) in Bardet-Biedl syndrome. J Hum Genet 61(5):447-50.

Scheidecker S, Etard C, Pierce NW, Geoffroy V, Schaefer E, Muller J, Chennen K, Flori E, Pelletier V, Poch O and others. 2014. Exome sequencing of Bardet-Biedl syndrome patient identifies a null mutation in the BBSome subunit BBIP1 (BBS18). J Med Genet 51(2):132-6. Schmidts M, Frank V, Eisenberger T, Al Turki S, Bizet AA, Antony D, Rix S, Decker C, Bachmann N, Bald M and others. 2013. Combined NGS approaches identify mutations in the 
intraflagellar transport gene IFT140 in skeletal ciliopathies with early progressive kidney Disease. Hum Mutat 34(5):714-24.

Schneider CA, Rasband WS, Eliceiri KW. 2012. NIH Image to ImageJ: 25 years of image analysis. Nat Methods 9(7):671-5.

Shapiro MB, Senapathy P. 1987. RNA splice junctions of different classes of eukaryotes: sequence statistics and functional implications in gene expression. Nucleic Acids Res 15(17):7155-74.

Sherry ST, Ward MH, Kholodov M, Baker J, Phan L, Smigielski EM, Sirotkin K. 2001. dbSNP: the NCBI database of genetic variation. Nucleic Acids Res 29(1):308-11.

Stankiewicz P, Sen P, Bhatt SS, Storer M, Xia Z, Bejjani BA, Ou Z, Wiszniewska J, Driscoll DJ, Maisenbacher MK and others. 2009. Genomic and genic deletions of the FOX gene cluster on 16q24.1 and inactivating mutations of FOXF1 cause alveolar capillary dysplasia and other malformations. Am J Hum Genet 84(6):780-91.

Stoetzel C, Bar S, De Craene JO, Scheidecker S, Etard C, Chicher J, Reck JR, Perrault I, Geoffroy V, Chennen K and others. 2016. A mutation in VPS15 (PIK3R4) causes a ciliopathy and affects IFT20 release from the cis-Golgi. Nat Commun 7:13586.

Tan R, Wang Y, Kleinstein SE, Liu Y, Zhu X, Guo H, Jiang Q, Allen AS, Zhu M. 2014. An evaluation of copy number variation detection tools from whole-exome sequencing data. Hum Mutat 35(7):899-907.

Taylor JC, Martin HC, Lise S, Broxholme J, Cazier JB, Rimmer A, Kanapin A, Lunter G, Fiddy S, Allan C and others. 2015. Factors influencing success of clinical genome sequencing across a broad spectrum of disorders. Nat Genet 47(7):717-726.

Thorvaldsdottir H, Robinson JT, Mesirov JP. 2013. Integrative Genomics Viewer (IGV): high-performance genomics data visualization and exploration. Brief Bioinform 14(2):178-92. Tyner C, Barber GP, Casper J, Clawson H, Diekhans M, Eisenhart C, Fischer CM, Gibson D, Gonzalez JN, Guruvadoo L and others. 2017. The UCSC Genome Browser database: 2017 update. Nucleic Acids Res 45(D1):D626-D634.

Yeo G, Burge CB. 2004. Maximum entropy modeling of short sequence motifs with applications to RNA splicing signals. J Comput Biol 11(2-3):377-94.

Zhu B, Zhu X, Wang L, Liang Y, Feng Q, Pan J. 2017. Functional exploration of the IFT-A complex in intraflagellar transport and ciliogenesis. PLoS Genet 13(2):e1006627. 


\section{Figure legends}

Figure 1. Identification of 2 mutations in IFT140 for a family explored by WGS.

(A) Pedigree of family A, which has 2 affected individuals. Segregation analysis of the 2 mutations noted M1: 2577+25G $>$ A and M2: 3454-488_4182+2588dup. Example of Sanger sequencing profiles for individual II.1. The breakpoint junction between exon 30 and intron 26 are shown.

(B) M1 analysis. Sanger sequencing was performed on RNA extracted from fibroblasts of individual II.1 and a healthy unrelated control amplified between exon 18 and exon 22.

(C) M2 analysis. Quantitative real-time PCR was performed on DNA from exon 30 in all individuals from family A and one unrelated control. DNA quantity from exon 30 of IFT140 was compared to 2 reference genes (HBB and $H M B S)$ using the absolute quantification method.

(D) M2 RNA expression in patient's II.1 skin fibroblasts is demonstrated by PCR amplification (PRMT9 as a control) and by Sanger sequencing.

(E) IFT140 expression in skin fibroblasts was revealed by western blot using anti-IFT140 antibody.

Figure 2. Patients' fibroblasts have reduced number of ciliated cells and mislocalized IFT140

(A) Number of ciliated cells were counted on serum deprived $(24 \mathrm{H})$ control and patient's skin fibroblasts fixed for immunofluorescence and stained with anti-IFT140 (red) and antiacetylated tubulin (green) antibodies. Nuclei were colored in blue (Dapi). 
(B) Based on 15 fields in three independent experiments (100-200 cells per experiment), mean percentages of ciliated cells are shown in a histogram together with corresponding standard deviation and $\mathrm{p}$-values (n.s.: non-significant, $*$ : $\mathrm{p}<0,0001)$.

(C) IFT140 localisation was assessed on serum deprived $(24 \mathrm{H})$ control and patient's skin fibroblasts fixed for immunofluorescence and stained with anti-IFT140 (red) and antiacetylated tubulin (green) antibodies. Nuclei were colored in blue (Dapi).

(D) Primary cilia containing IFT140 were counted based on three independent experiments (60-200 ciliated cells per experiment), mean percentages are shown in a histogram together with corresponding standard deviation and p-values (n.s.: non-significant, *: $p<0,0005$ ).

\section{Figure 3. Mutations in IFT140}

(A) Pedigrees of 7 additional families with affected individuals carrying the tandem duplication.

(B) Pedigrees of additional families with $I F T 140$ pathogenic variants.

\section{Figure 4. Schematic representation of IFT140 and of the tandem duplication}

(A) IFT140 extends over $105.6 \mathrm{~kb}$ in chromosomal region $16 \mathrm{p} 13.3$ and contains 31 exons encoding a 1462 amino acids protein containing two repeated domains, 5 WD repeats and 9 tetratricopeptide (TPR) repeats. Previously reported mutations in IFT140 are represented using a black "asterisk" whereas novel mutations are colored in red. In particular, the two mutations from family $\mathrm{A}$ are also shown in introns 20 (c.2577+25G>A) and 30 (c.3454490_4182+2588dup). The tandem duplication (black horizontal bar) spans from exon 27 to 30 (6.7 kb). The breakpoints are located within Alu elements (AluJb and AluJr). 
(B) Breakpoint junction sequence of affected individuals with tandem duplication. Breakpoint junction sequence is aligned to the proximal and distal genomic references, respectively AluJr (chr16:1565570-1565697) and AluJb (chr16:1571239-1571365), and color-matched. Microhomology at the breakpoint is indicated in red. The aligned genomic region is $128 \mathrm{bp}$ long showing $81 \%$ of sequence identity.

(C) Proposed rearrangement of Alu-Alu mediated duplication in affected individuals. 


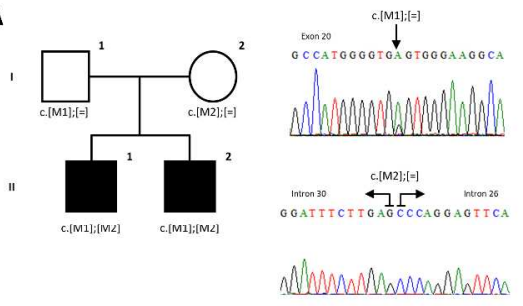

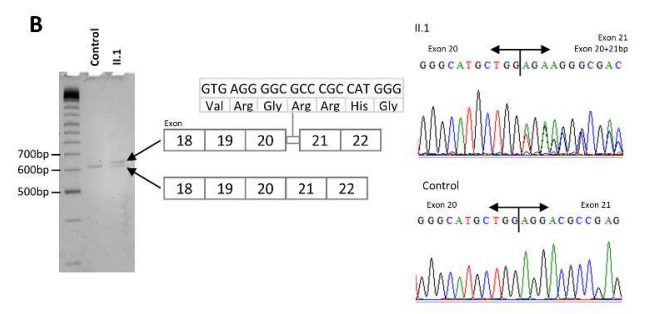

c

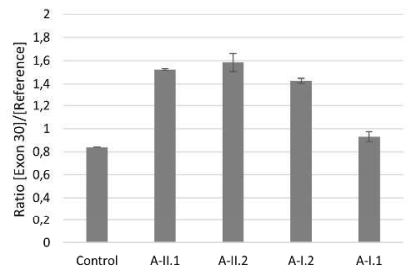

D

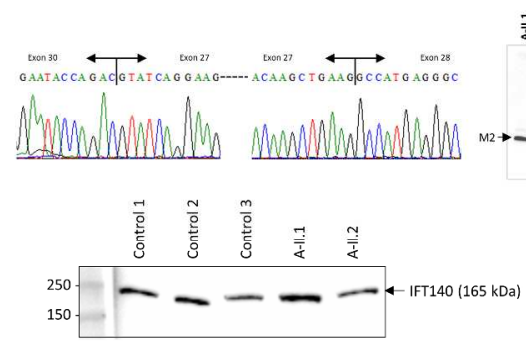

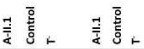

Figure 1. Identification of 2 mutations in IFT140 for a family explored by WGS.

(A) Pedigree of family A, which has 2 affected individuals. Segregation analysis of the 2 mutations noted M1: $2577+25 G>A$ and M2: 3454-488_4182+2588dup. Example of Sanger sequencing profiles for individual II.1. The breakpoint junction between exon 30 and intron 26 are shown.

(B) M1 analysis. Sanger sequencing was performed on RNA extracted from fibroblasts of individual II.1 and a healthy unrelated control amplified between exon 18 and exon 22.

(C) M2 analysis. Quantitative real-time PCR was performed on DNA from exon 30 in all individuals from family $A$ and one unrelated control. DNA quantity from exon 30 of IFT140 was compared to 2 reference genes (HBB and HMBS) using the absolute quantification method.

(D) M2 RNA expression in patient's II.1 skin fibroblasts is demonstrated by PCR amplification (PRMT9 as a control) and by Sanger sequencing.

(E) IFT140 expression in skin fibroblasts was revealed by western blot using anti-IFT140 antibody.

$297 \times 166 \mathrm{~mm}(300 \times 300$ DPI $)$ 
C

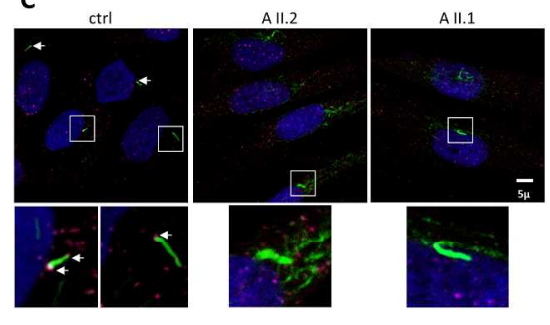

D

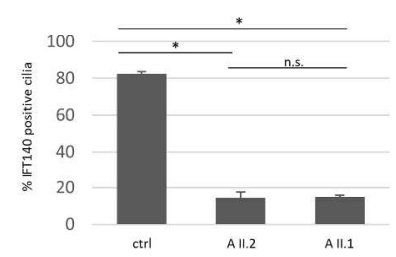

Figure 2. Patients' fibroblasts have reduced number of ciliated cells and mislocalized IFT140 (A) Number of ciliated cells were counted on serum deprived $(24 \mathrm{H})$ control and patient's skin fibroblasts fixed for immunofluorescence and stained with anti-IFT140 (red) and anti-acetylated tubulin (green) antibodies. Nuclei were colored in blue (Dapi).

(B) Based on 15 fields in three independent experiments (100-200 cells per experiment), mean percentages of ciliated cells are shown in a histogram together with corresponding standard deviation and p-values (n.s.: non-significant, $*$ : $\mathrm{p}<0,0001)$.

(C) IFT140 localisation was assessed on serum deprived $(24 \mathrm{H})$ control and patient's skin fibroblasts fixed for immunofluorescence and stained with anti-IFT140 (red) and anti-acetylated tubulin (green) antibodies. Nuclei were colored in blue (Dapi).

(D) Primary cilia containing IFT140 were counted based on three independent experiments (60-200 ciliated cells per experiment), mean percentages are shown in a histogram together with corresponding standard deviation and p-values (n.s.: non-significant, $*$ : $p<0,0005)$. 
A

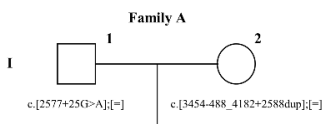

II
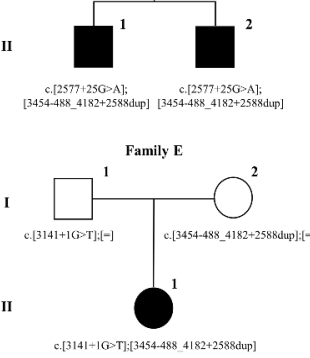

B

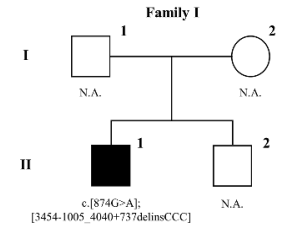

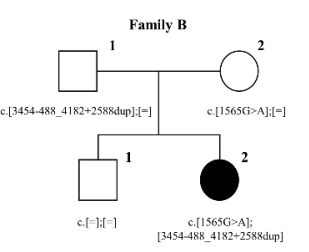
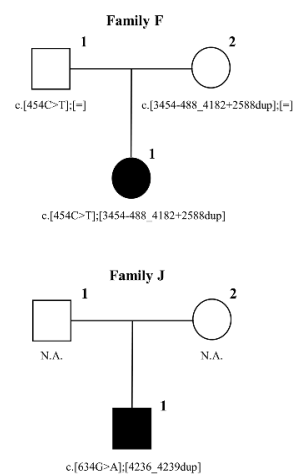
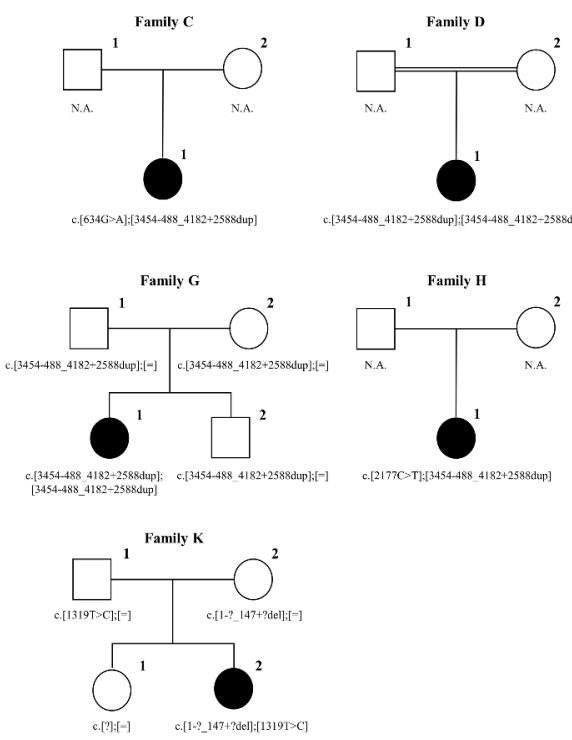

Figure 3. Mutations in IFT140

(A) Pedigrees of 7 additional families with affected individuals carrying the tandem duplication. (B) Pedigrees of additional families with IFT140 pathogenic variants.

$558 \times 325 \mathrm{~mm}(300 \times 300$ DPI $)$ 
A
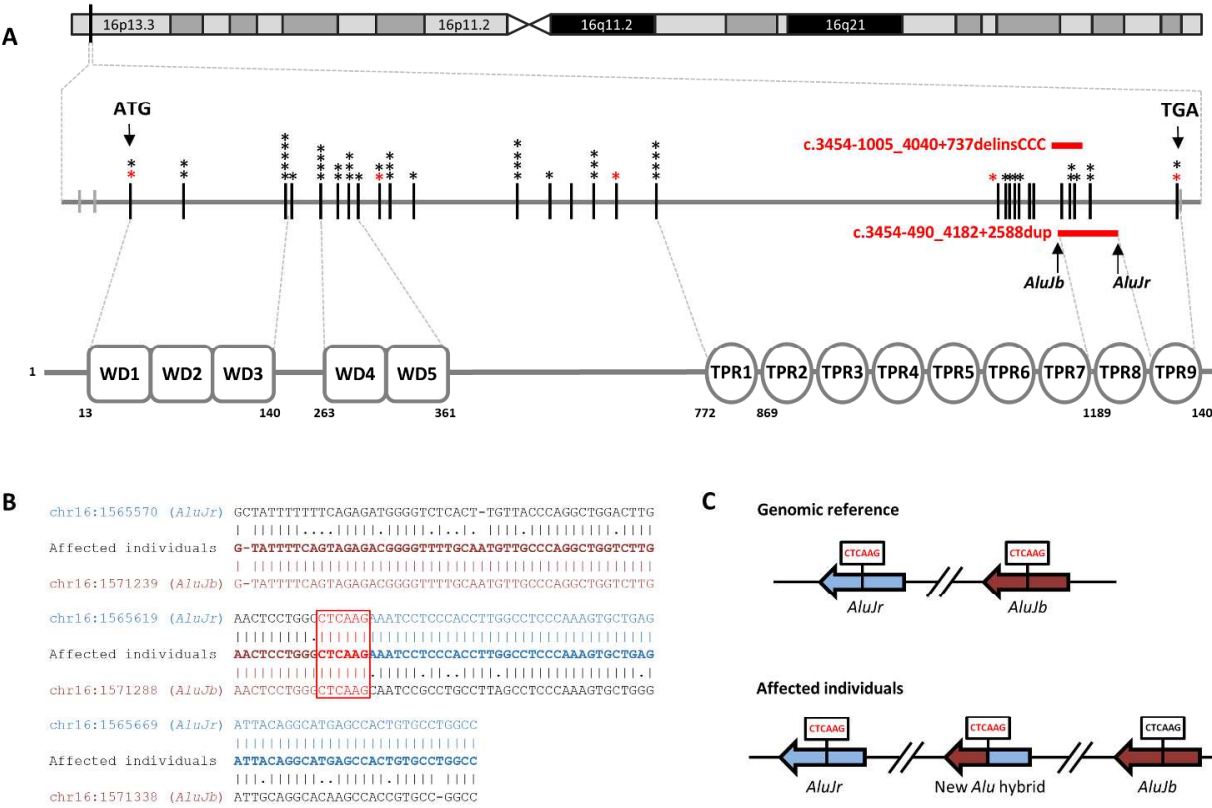

Figure 4. Schematic representation of IFT140 and of the tandem duplication

(A) IFT140 extends over $105.6 \mathrm{~kb}$ in chromosomal region 16p13.3 and contains 31 exons encoding a 1462 amino acids protein containing two repeated domains, 5 WD repeats and 9 tetratricopeptide (TPR) repeats. Previously reported mutations in IFT140 are represented using a black "asterisk" whereas novel mutations are colored in red. In particular, the two mutations from family A are also shown in introns 20

(c.2577+25G $>$ A) and 30 (c.3454-490_4182+2588dup). The tandem duplication (black horizontal bar) spans from exon 27 to $30(6.7 \mathrm{~kb})$. The breakpoints are located within Alu elements (AluJb and AluJr).

(B) Breakpoint junction sequence of affected individuals with tandem duplication. Breakpoint junction sequence is aligned to the proximal and distal genomic references, respectively AluJr (chr16:15655701565697) and AluJb (chr16:1571239-1571365), and color-matched. Microhomology at the breakpoint is indicated in red. The aligned genomic region is $128 \mathrm{bp}$ long showing $81 \%$ of sequence identity.

(C) Proposed rearrangement of Alu-Alu mediated duplication in affected individuals.

$$
232 \times 153 \mathrm{~mm} \text { ( } 300 \times 300 \text { DPI) }
$$




\section{SUPPLEMENTARY METHODS}

\section{Whole Exome Sequencing}

Whole Exome Sequencing (WES) was performed for the two affected siblings from family A (A-II.1 and A-II.2) by the IGBMC (Institute of Genetics and Molecular and Cellular Biology) Microarray and Sequencing platform. Exons of DNA samples were captured with in-solution enrichment methodology (Agilent SureSelect All Exon XT2 50 Mb Kit) and sequenced with an Illumina HiSeq 2500 instrument as paired-end 100 bp reads, in order to reach an average sequencing depth of $80 \mathrm{x}$ for each sample. The sequence reads were aligned to the reference sequence of the human genome (GRCh37) using the Burrows-Wheeler Aligner (BWA V7.12) (Li and Durbin, 2010). The HaplotypeCaller module of the Genome Analysis ToolKit (GATK, v.3.4.46) (DePristo, et al., 2011) was used for calling both SNV and indel.

\section{Targeted Exome Sequencing}

\section{Leber panel}

Targeted exome sequencing of 14 full genes related to Leber congenital amaurosis was performed for 126 patients (including family B, C, D, E and I). Illumina compatible precapture barcoded genomic DNA libraries were constructed according to the manufacturer's sample preparation protocol (Ovation Ultralow, Nugen Technologies). Exons of DNA samples were captured with in-solution enrichment methodology (Agilent SureSelect custom panel) and sequenced with an Illumina HiSeq2500 (Paired-End sequencing 2x125 bases, Rapid Mode, 80 libraries per lane). Bioinformatics analysis was performed as described in Gerber et al (Gerber, et al., 2016) using an in house pipeline (POLYWEB). 


\section{RP panel}

Targeted exome sequencing of 267 genes related to retinitis pigmentosa was performed for 117 patients (including family J). Exons of DNA samples were captured with in-solution enrichment methodology (Agilent QXT SureSelect custom panel) and sequenced with an Illumina NextSeq 550 instrument (Paired-End sequencing 2x150 bases, 48 libraries per lane). SNVs and indels were called with the Genome Analysis Toolkit v.3.4.46 thanks to our in house pipeline (STARK) and following the GATK best practice.

\section{Ciliome panel}

Targeted exome sequencing of 1221 ciliary candidate genes including genes related to ciliopathies like Jeune asphyxiating thoracic dystrophy, Mainzer-Saldino syndrome, BardetBiedl syndrome, Joubert syndrome and Senior Loken was performed for 364 patients (including families C, D, I and K). Sequencing was conducted using a custom SureSelect capture kit (Agilent Technologies) targeting 4.5 Mb of 20,168 exons, and performed on SOLiD5500XL (Life Technologies) or HiSeq (Illumina). Bioinformatics analysis was performed as described in Grampa et al (Grampa, et al., 2016) using an in house pipeline (POLYWEB). The mean depth of coverage obtained was greater than $165 \mathrm{x}$, with $\geq 89 \%$ of the bases covered at least $15 x$. In order to evaluate duplication and large deletion events, for each individual the relative read count for each targeted region was determined as the ratio of the read count for that region divided by the total absolute read counts of all targeted regions of the design. The ratio of the relative read count of a region in a given individual over the average relative read counts in other individuals of the run resulted in the estimated copy number for that region in that individual. 


\section{Missense pathogenicity analysis}

For the 2 novel missenses identified in this study, conservation has been assessed using the multiple sequence alignment available from the eggnog database (KOG3717, (Huerta-Cepas, et al., 2016)) and they were analyzed thanks to the PolyPhen-2, SIFT and MutationTaster softwares (Adzhubei, et al., 2010; Kumar, et al., 2009; Schwarz, et al., 2010) 


\begin{tabular}{|c|c|c|c|c|c|c|c|}
\hline \multicolumn{8}{|c|}{ Perrault et al 2012 (Perrault, et al., 2012) and this study } \\
\hline MSS & c. $932 \mathrm{~A}>\mathrm{G}$ (p.Tyr311Cys) & Exon 9 & $1 / 120$ & c.857_860del (p.Ile286Lysfs*6) & Exon 8 & $1 / 120$ & \\
\hline MSS & c.1990G>A (p.Glu664Lys) & Exon 17 & $31 / 120$ & c.1990G>A (p.Glu664Lys) & Exon 17 & $31 / 120$ & \\
\hline MSS & c.1990G>A (p.Glu664Lys) & Exon 17 & $31 / 120$ & c.1990G >A (p.Glu664Lys) & Exon 17 & $31 / 120$ & \\
\hline JATD & c. $2399+1 \mathrm{G}>\mathrm{T}(\mathrm{p} . ?)$ & Intron 19 & $5 / 120$ & c.634G>A (p.Gly212Arg) & Exon 7 & $7 / 120$ & \\
\hline MSS & c.1565G $>$ A (p.Gly522Glu) & Exon 14 & $4 / 120$ & c.3454-488_4182+2588dup p.(Tyr1152_Thr1394dup) & Introns 2630 & $10 / 120$ & Family B \\
\hline JATD/MSS & c. $874 \mathrm{G}>\mathrm{A}$ (p.Val292Met) & Exon 8 & $4 / 120$ & $c .3454-1005$ 4040+737delinsCCC, $\left(p . T y r 1152 A s p f s^{*} 14\right)$ & Exons 27-30 & $1 / 120$ & Family I \\
\hline MSS & c.1727G>A (p.Arg576Gln) & Exon 15 & $1 / 120$ & $2^{\text {nd }}$ allele not found & & & \\
\hline MSS & $\begin{array}{l}\text { c.489C }>\mathrm{T} \text { (p.Gly163Gly), and c.488 491 del (p.Glu164Thrfs*10) } \\
\text { from creation of additional donor splice site }\end{array}$ & Exon 5 & $1 / 120$ & $2^{\text {nd }}$ allele not found & & & \\
\hline JATD & c.454C>T (p.Leu152Phe) & Exon 5 & $3 / 120$ & c.454C>T (p.Leu152Phe) & Exon 5 & $3 / 120$ & \\
\hline JATD & c.2278C>T (p.Arg759*) & Exon 19 & $2 / 120$ & $2^{\text {nd }}$ allele not found & & & \\
\hline MSS & c. $2399+1 \mathrm{G}>\mathrm{T}(\mathrm{p} . ?)$ & Intron 19 & $5 / 120$ & c.4078T>C (p.Cys1360Arg) & Exon 30 & $1 / 120$ & \\
\hline MSS & c.418G>A (p.Gly140Arg) and c.800A $>$ G (p.Glu267Gly) & Exons 5/7 & $1 / 120$ & c.490G>T (p.Glu164*) & Exon 6 & $1 / 120$ & \\
\hline JATD & c.2399+1G>T (p.?) & Intron 19 & $5 / 120$ & $2^{\text {nd }}$ allele not found & & & \\
\hline JATD & c. $4058 \mathrm{G}>\mathrm{C}$ (p.Pro1353Arg) & Exon 30 & $1 / 120$ & $2^{\text {nd }}$ allele not found & & & \\
\hline JATD & c.2360 T>C (p.Asp787Gly) & Exon 19 & $1 / 120$ & $2^{\text {nd }}$ allele not found & & & \\
\hline JATD & c.1541 A>T (p.Leu514His) & Exon 14 & $1 / 120$ & $2^{\text {nd }}$ allele not found & & & \\
\hline JATD & c.329G $>$ A (p.Arg110His) & Exon 4 & $1 / 120$ & $2^{\text {nd }}$ allele not found & & & \\
\hline JATD & c.481C $>$ A (p.Pro161Thr) & Exon 5 & $2 / 120$ & $2^{\text {nd }}$ allele not found & & & \\
\hline
\end{tabular}




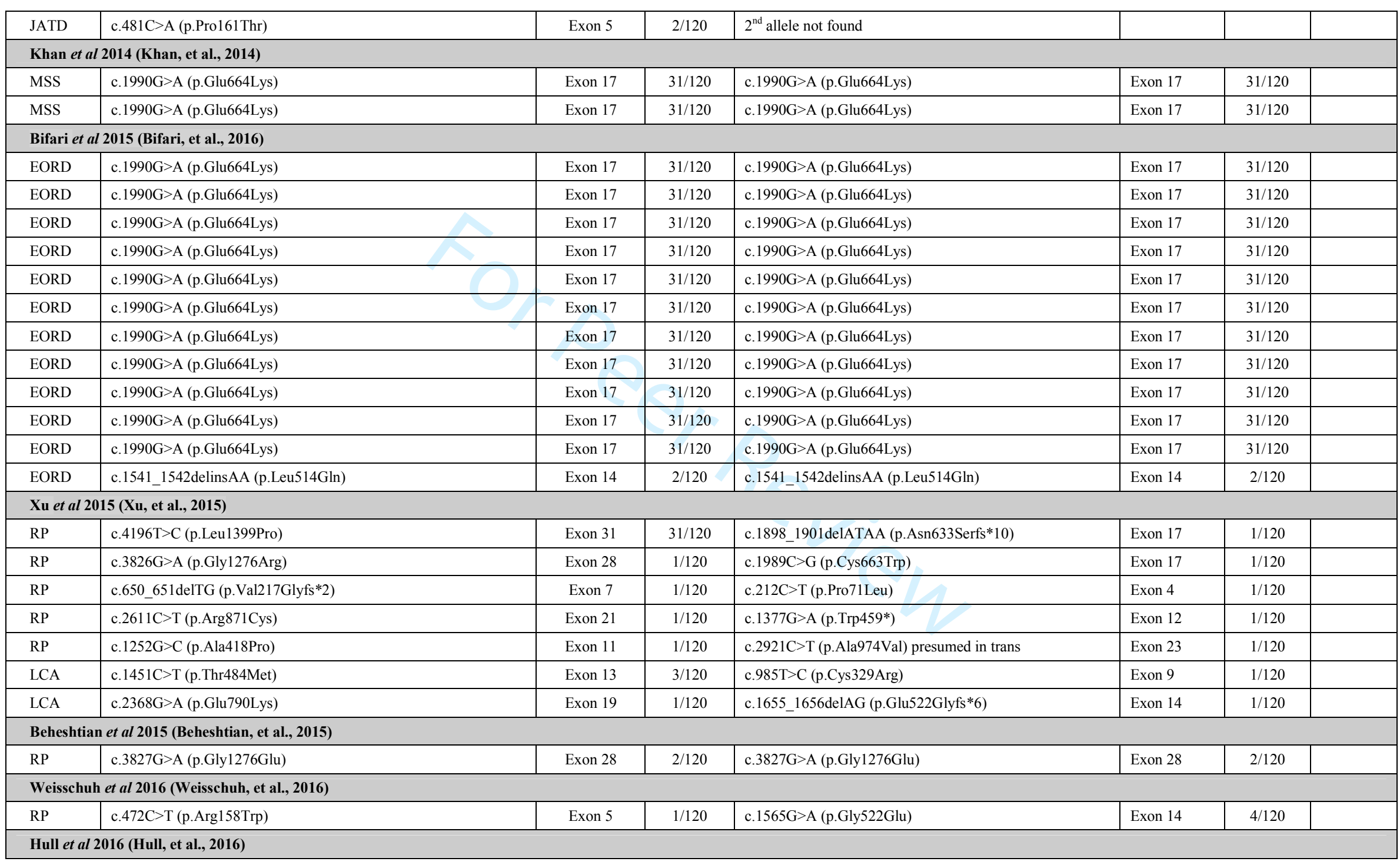




\begin{tabular}{|c|c|c|c|c|c|c|c|}
\hline $\mathrm{RP}$ & c.1451C $>$ T (p.Thr484Met) & Exon 13 & $3 / 120$ & c. $1451 \mathrm{C}>\mathrm{T}$ (p.Thr484Met) & Exon 13 & $3 / 120$ & \\
\hline RP & c. $2399+1 \mathrm{G}>\mathrm{T}(\mathrm{p} . ?)$ & Intron 19 & $5 / 120$ & c.2815T >C (p.Ser939Pro) & Exon 22 & $1 / 120$ & \\
\hline $\mathrm{RP}$ & c.998G>A (p.Cys333Tyr) & Exon 9 & $4 / 120$ & c. $998 \mathrm{G}>$ A (p.Cys333Tyr) & Exon 9 & $4 / 120$ & \\
\hline $\mathrm{RP}$ & c. $998 \mathrm{G}>$ A (p.Cys333Tyr) & Exon 9 & $4 / 120$ & c. $998 \mathrm{G}>$ A (p.Cys333Tyr) & Exon 9 & $4 / 120$ & \\
\hline $\mathrm{RP}$ & c.1021G>A (p.Ala341Thr) & Exon 10 & $1 / 120$ & c.1422_23insAA (p.Arg475Asnfs*14) & Exon 12 & $1 / 120$ & \\
\hline \multicolumn{8}{|c|}{ Pena-Padilla et al 2016 (Pena-Padilla, et al., 2016) } \\
\hline OTCS & c. $3141+1 \mathrm{G}>\mathrm{T}(\mathrm{p} . ?)$ & Exon 24 & $2 / 120$ & c.-11_6del (p.?) & Exon 3 & $1 / 120$ & \\
\hline \multicolumn{8}{|c|}{ Bayat et al 2017 (Bayat, et al., 2017) } \\
\hline SB & c.634G>A (p.Gly212Arg) & Exon 7 & $7 / 120$ & c. $2278 \mathrm{C}>\mathrm{T}\left(\mathrm{p} . \operatorname{Arg} 759^{*}\right)$ & Exon 19 & $2 / 120$ & \\
\hline \multicolumn{8}{|c|}{ Helm et al 2017 (Helm, et al., 2017) } \\
\hline MSS & c.634G >A (p.Gly212Arg) & Exon 7 & $7 / 120$ & c. $634 \mathrm{G}>\mathrm{A}$ (p.Gly212Arg) & Exon 7 & $7 / 120$ & \\
\hline \multicolumn{8}{|c|}{ This study } \\
\hline MSS & c.2577+25G>A (p.Leu859_Glu860insValArgGlyAlaArgHisGly) & Intron 20 & $1 / 120$ & c.3454-488_4182+2588dup (p.Tyr1152_Thr1394dup) & Introns $26-30$ & $10 / 120$ & Family A \\
\hline MSS & c.634G>A (p.Gly212Arg) & Exon 7 & $7 / 120$ & c.3454-488_4182+2588dup (p.Tyr1152_Thr1394dup) & Introns $26-30$ & $10 / 120$ & Family C \\
\hline MSS & c.3454-488_4182+2588dup (p.Tyr1152_Thr1394dup) & Introns $26-30$ & $10 / 120$ & c.3454-488_4182+2588dup (p.Tyr1152_Thr1394dup) & Introns $26-30$ & $10 / 120$ & Family D \\
\hline JATD/MSS & c. $3141+1 \mathrm{G}>\mathrm{T}(\mathrm{p} . ?)$ & Exon 24 & $2 / 120$ & c.3454-488_4182+2588dup (p.Tyr1152_Thr1394dup) & Introns $26-30$ & $10 / 120$ & Family E \\
\hline MSS & c.454C $>$ T (p.Leu152Phe) & Exon 5 & $3 / 120$ & c.3454-488_4182+2588dup (p.Tyr1152_Thr1394dup) & Introns $26-30$ & $10 / 120$ & Family F \\
\hline MSS & c.3454-488_4182+2588dup (p.Tyr1152_Thr1394dup) & Introns $26-30$ & $10 / 120$ & c.3454-488_4182+2588dup (p.Tyr1152_Thr1394dup) & Introns $26-30$ & $10 / 120$ & Family G \\
\hline $\mathrm{MSS} / \mathrm{SB}$ & c.2177C $>$ T (p.Pro726Leu) & Exon 18 & $1 / 120$ & c.3454-488_4182+2588dup (p.Tyr1152_Thr1394dup) & Introns $26-30$ & $10 / 120$ & Family $\mathrm{H}$ \\
\hline $\mathrm{RP}$ & c. $634 \mathrm{G}>\mathrm{A}$ (p.Gly212Arg) & Exon 7 & $7 / 120$ & c.4236_4239dup (p.Tyr1414Leufs*48) & Exon 31 & $1 / 120$ & Family J \\
\hline $\begin{array}{c}\text { MSS } \\
\text { (mild) }\end{array}$ & c.1-?_147+?del, start loss & Exon 3 & $1 / 120$ & c.1319T>C (p.Leu440Pro) & Exon 11 & $1 / 120$ & Family K \\
\hline
\end{tabular}

Table S1. Previously reported and novel mutations in IFT140.

Mutations are reported only once per family. Those reported in this study are in bold and those described for the first time are also in italic. Mutation allelic counts are reported for only one affected individual per family. It is to notice that some studies (i.e. Bifari et al) have analyzed consanguineous families from the same region increasing the global allelic count. EORD: early-onset retinal dystrophy; JATD: Jeune asphyxiating thoracic dystrophy; MSS: Mainzer-Saldino Syndrome; OCTS: Opitz trigonocephaly C syndrome; RP: retinitis pigmentosa; SB: Sensenbrenner syndrome. 


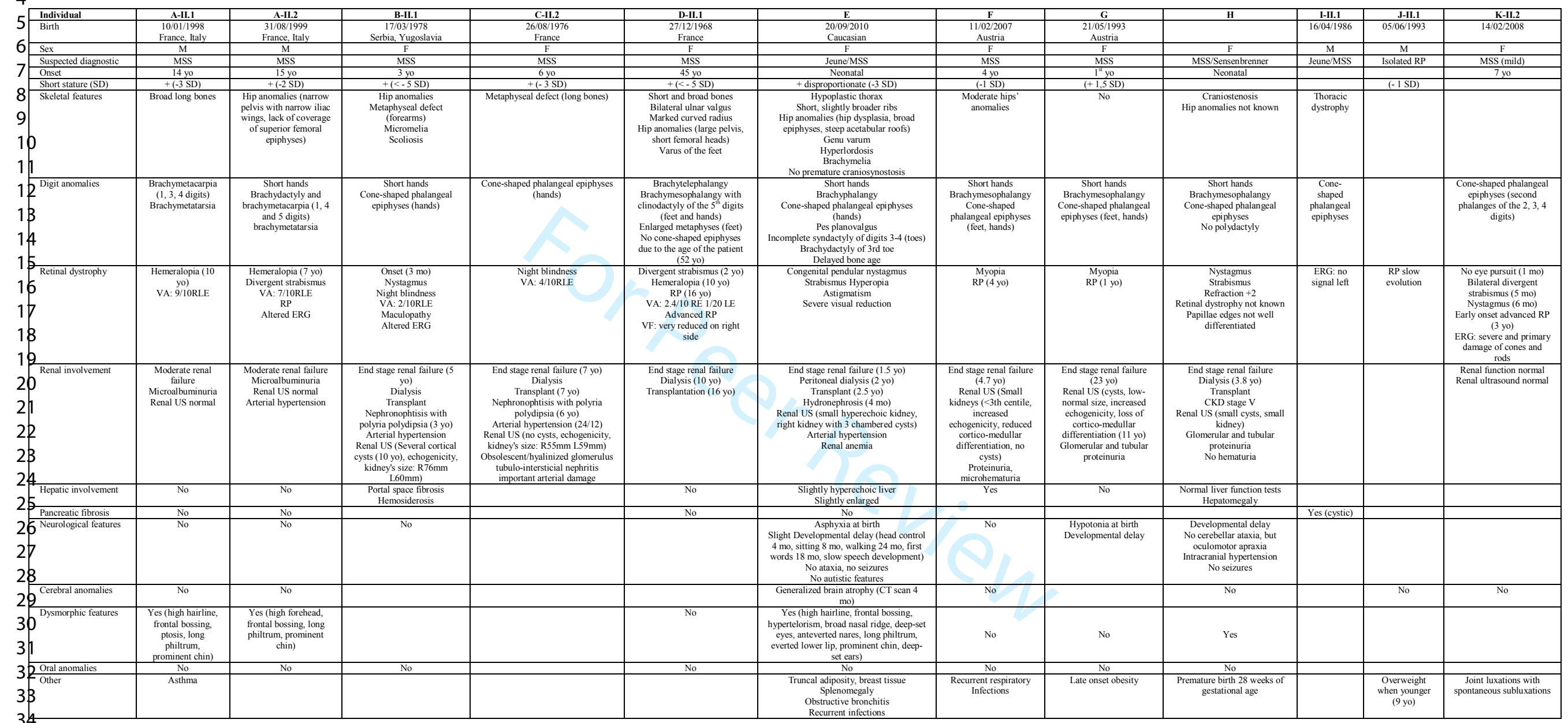

Table S2 Clinical Features of MSS-affected individuals harboring compound-heterozygous mutations in IFT140. CKD: Cystic Kidney Disease, CT: Computed Tomography, ERG: Electroretinogram, F: Female, L: Left, LE: Left Eye, M: Male, mo: month old, MSS: Mainzer-Saldino Syndrome, R: Right, RE: Right Eye, RLE: Right and left Eye, RP: Retinitis Pigmentosa, SD: standard deviation, US: Ultrasound, VA: Visual acuity, VF: visual field, yo: years old. 


\begin{tabular}{|c|c|c|c|c|c|}
\hline Application & Gene & RefSeq & Name & Forward (5'-3') & Reverse (5'-3') \\
\hline DNA c. $2577+25 \mathrm{G}>\mathrm{A}$ & IFT140 & NM_014714.3 & IFT140-ex20 & GATGACTACTTGCCCCAGGA & CACACCTGACAGGCACACAC \\
\hline DNA breakpoint TD & & & IFT140-intron30F_intron26R & CCGGAGTAGCTGGGATTACA & CTGTCTAGCTGGGGTGGGTA \\
\hline DNA c. $1565 \mathrm{G}>\mathrm{A}$ & & & IFT140-ex14 & TGAGCGAGTGAATGAGTGGA & CGGTGTTAAAATGGGCACCT \\
\hline cDNA c. $2577+25 \mathrm{G}>\mathrm{A}$ & & & IFT140-RT-PCR-ex18-19F_ex22R & ATCAAAAGTGAGGCCGTCTG & GCGTGTCCGACTTCTCGTA \\
\hline cDNA TD & & & IFT140-RT-PCR-ex30F_ex28R & AAGCAGTGTGAGCTGCTCCT & GGGCACAAGCGTCATAAAAG \\
\hline cDNA control & PRMT9 & NM_001304458 & PRMT9-RT-PCR-ex3F_ex6R & GTGGAACGCTGGCACTTTAT & CAATTAGCACTTTCACCTTTGG \\
\hline qPCR & IFT140 & NM_014714.3 & IFT140-QPCR-ex30F_ex30R & CATAGAAAGTTTCCTCCTGCCAT & TCTGGTTCCTCCAGGAGCA \\
\hline qPCR & $H M B S$ & NM_000190 & HMBS-QPCR- & CACAGCACTCCCACTGACAAC & GAGGGAGGCGATAGTAGGACC \\
\hline qPCR & $H B B$ & NM_000518 & BGLOB-QPCR-ex1F_ex1R & ACACAACTGTGTTCACTAGC & CAACTTCATCCACGTTCACC \\
\hline Duplex PCR & IFT140 & NM_014714.3 & IFT140-intron30F_intron26R & CCCAAAGCGTCATTTCTGGTGTTC & CCCAGGGTCAGGTGATCTTCCTA \\
\hline & BBS12 & NM_152618 & BBS12-ex2F_ex2R & AGTTCTCATTGAGGGTGACCT & GCCAGAGATGAAGCCAGCCA \\
\hline
\end{tabular}

Table S3 List and characteristics of primers used in this study. TD: Tandem duplication of exon 27-30 


\begin{tabular}{lccc} 
Name primary antibodies & Applications & Producer & Conditions \\
\hline Mouse anti-Acetylated $\alpha$-Tubulin & WB, IF & Abcam \#ab24610 & IF: $1 / 200$ \\
Rabbit anti-IFT140 & WB, IF & Proteintech \#17460-1-AP & WB: $1 / 100$ \\
Mouse anti- $\beta$-Tubulin & WB & Euromedex \# TUB-2A2 & $1 / 2500$ \\
\hline & & & \\
Name secondary antibodies & & Thermo Scientific \#A16012 & $1 / 500$ \\
\hline Donkey anti-Mouse IgG (H+L), FITC conjugate & IF & & \\
& & Thermo Scientific \#A-11011 & $1 / 500$ \\
Goat anti-Rabbit IgG (H+L) Alexa Fluor 568 conjugate & IF & & Santa Cruz \#sc-2955 \\
Chicken anti-Rabbbit IgG-HRP & WB & Santa Cruz \#sc-2060 & $1 / 5000$ \\
Goat anti mouse IgG-HRP & & & \\
\hline
\end{tabular}

Table S4. List of antibodies used in this study. IF: immunofluorescence, WB Western Blot. 
Figure S1. Duplex PCR profiles on a LabChip GX (Perkin Elmer) for a rapid detection of the IFT140 tandem duplication (see Table S3 for primers details). Normal samples harbor a single band (BBS12) whereas homozygous or heterozygous carriers for the tandem duplication show an additional band specific for the duplication breakpoint. 
Type of sequence variant

Total number of variants

After exclusion of variants with an allele frequency $>1 \%$ (extracted from dbSNP, the Exome Variant Server and the ExAC database or our internal exome database)

After exclusion of variants found at the homozygous state and more than once at the heterozygous state in 90 control exomes

After exclusion of 5'UTR, 3'UTR, downstream, upstream and intron locations without local splice effect prediction (from the "localSpliceEffect" field of Alamut-Batch)

After exclusion of synonymous variants without local splice effect prediction (from the "localSpliceEffect" field of Alamut-Batch)

After selection of variants consistent with recessive transmission (compound heterozygous, homozygous variants).
A-II.1

\begin{tabular}{|c|c|c|c|}
\hline \multicolumn{2}{|c|}{ A-II.1 } & \multicolumn{2}{c}{ A-II.2 } \\
\hline SNV & indel & SNV & indel \\
\hline 49489 & 2168 & 49418 & 2133 \\
\hline 6528 & 1038 & 6517 & 1017 \\
\hline 1159 & 90 & 1029 & 72 \\
\hline 517 & 20 & 458 & 12 \\
\hline 417 & 20 & 373 & 12 \\
\hline \multicolumn{3}{|c|}{2 compound heterozygous in } \\
\hline \multicolumn{3}{|c|}{ PLEKHA8 } \\
\hline
\end{tabular}

Table S5 Summary of the whole exome sequencing results from family A

WES data processing and variant calling revealed respectively 51,657 and 51,551 SNV and indels in individual A-II.1 and A-II.2. Variant filtering using stringent criteria reduced the number of genetics variants to respectively 437 and 385 variants per proband. To identify variants consistent with autosomal recessive inheritance, we kept only compound shared heterozygous or homozygous variants, reducing the number of variants to 2 heterozygous variants in the PLEKHA8 gene: NM_001197026.1:c.1517_1518insAT (p.Leu507Phefs*27) and NM_001197026.1:c.1522del (p.Tyr508Metfs*25). Both variants being always supported on the same reads (as shown in the IGV view below), they are in cis and are probably an artifact due to a bad reads alignment. So, no candidate gene was found by the WES analyses.

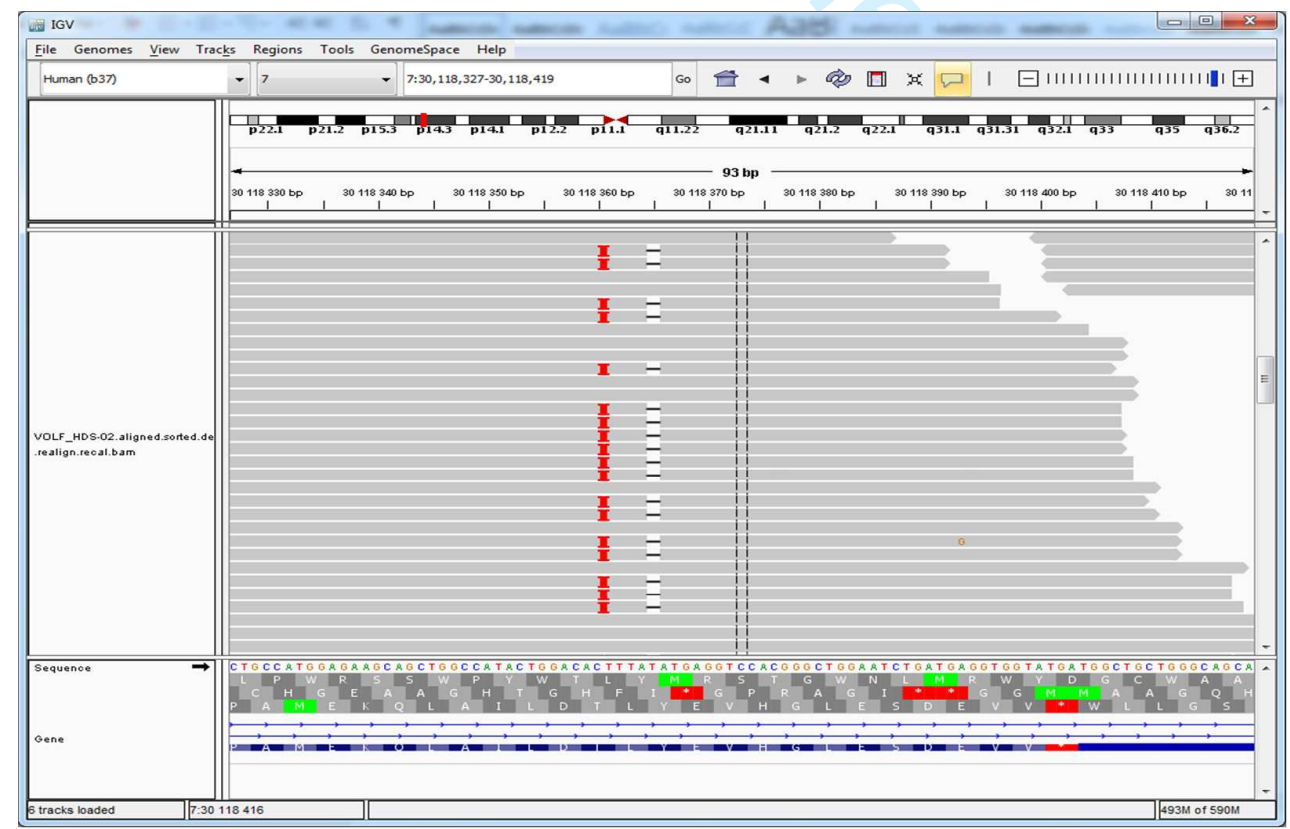

John Wiley \& Sons, Inc. 
2

3

4

5

6

7

8

9

10

11

12

13

14

15

16

17

18

19

20

21

22

23

24

26

27

28

29

30

31

32

33

34

35

36

37

39

40

41

42

43

44

45

46

47

48

49

50

51

52

53

54

55

56

57

58

59

60

John Wiley \& Sons, Inc. 


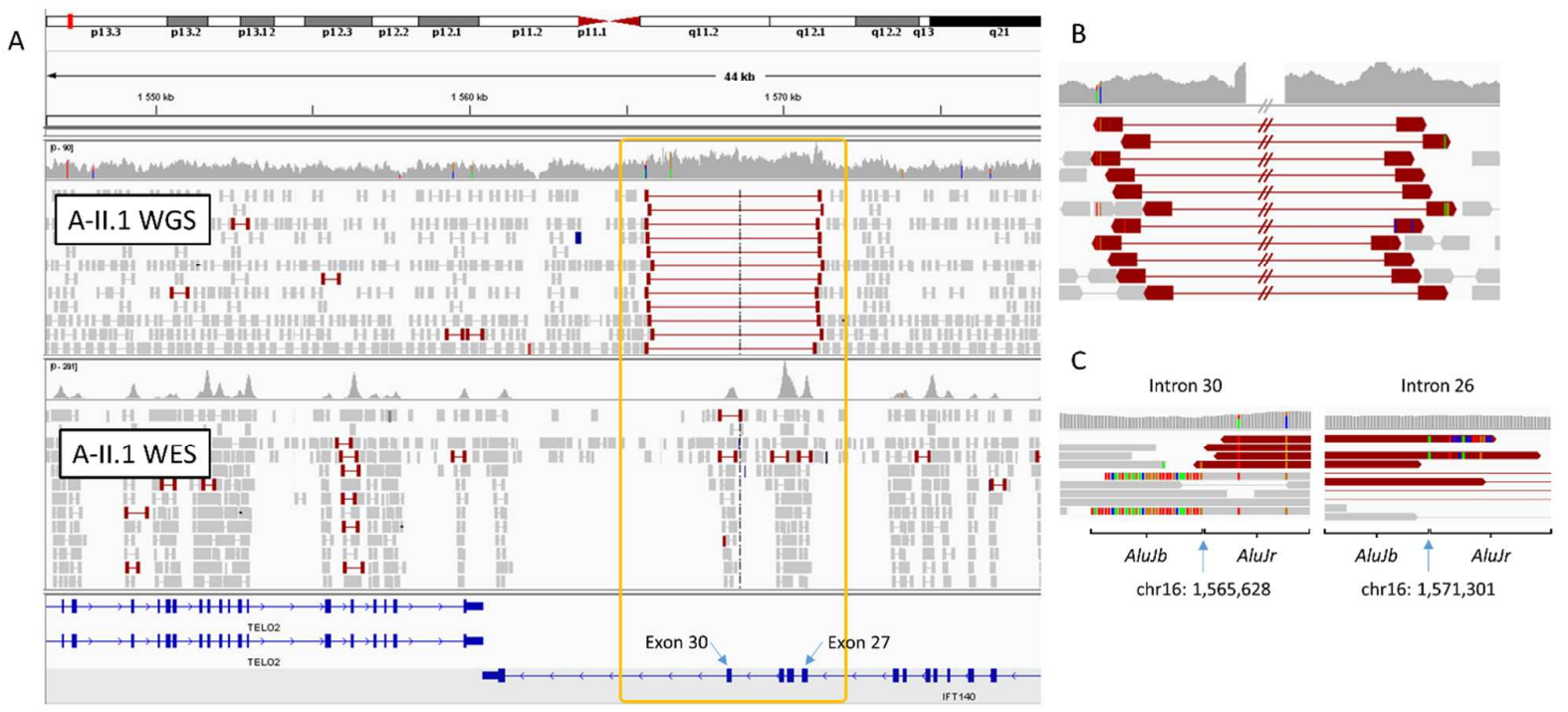

Figure S2. Next generation sequencing data from patient A-II.1 displayed around IFT140, in particular from exon 27 to exon 30 highlighting the tandem duplication.

(A) Comparison between whole genome sequencing (WGS) and whole exome sequencing (WES) data from patient A-II.1. The reads are displayed as pairs and sorted according to their insert size using IGV (Thorvaldsdottir, et al., 2013).

(B) Highlight of the WGS read pairs at the breakpoint junctions showing the typical drawing (read pairs pointing in opposite direction) for tandem duplications in direct orientation.

(C) Highlight of the WGS read pairs at the breakpoints including soft clipped bases. The left breakpoint in intron 30 overlaps the $A l u J r$ while the right breakpoint in intron 26 overlaps the $A l u J b$. Analysis of the reads and the split reads that are misaligned allowed us to define the exact position of the duplication. 


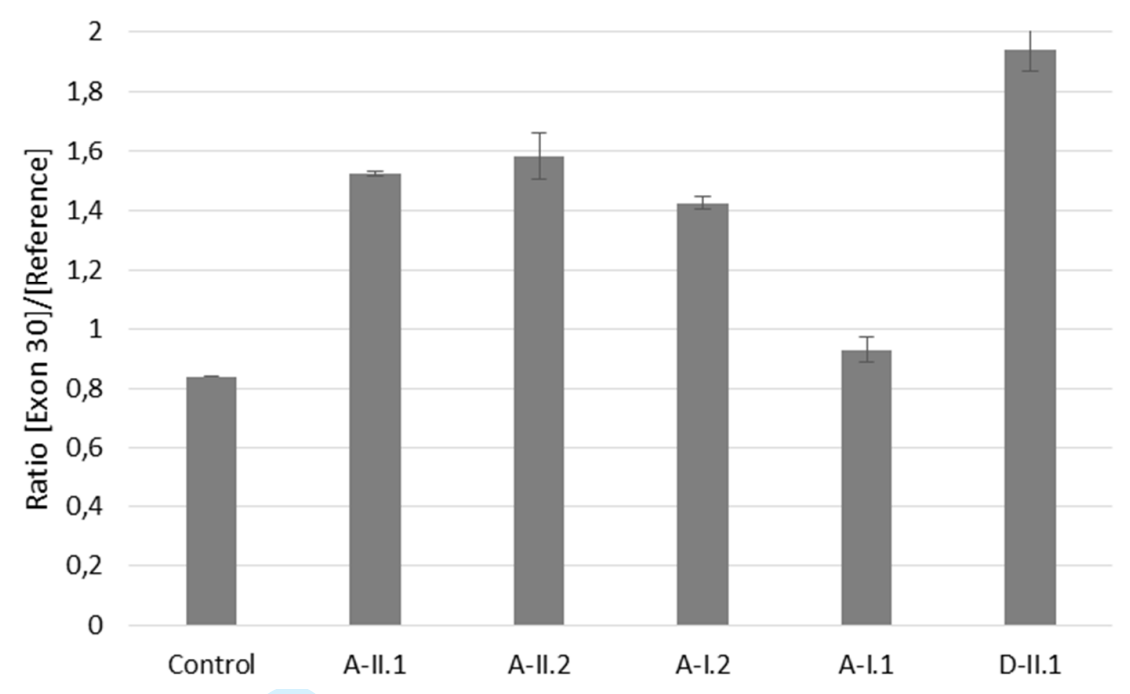

Figure S3. Homozygous duplication in IFT140 validated by quantitative real-time PCR.

Quantitative real-time PCR was performed on DNA from exon 30 in all individuals from family A and D as well as in one unrelated control. DNA quantity from exon 30 of IFT140 was compared to 2 reference genes $(H B B$ and $H M B S)$ using the absolute quantification method. 

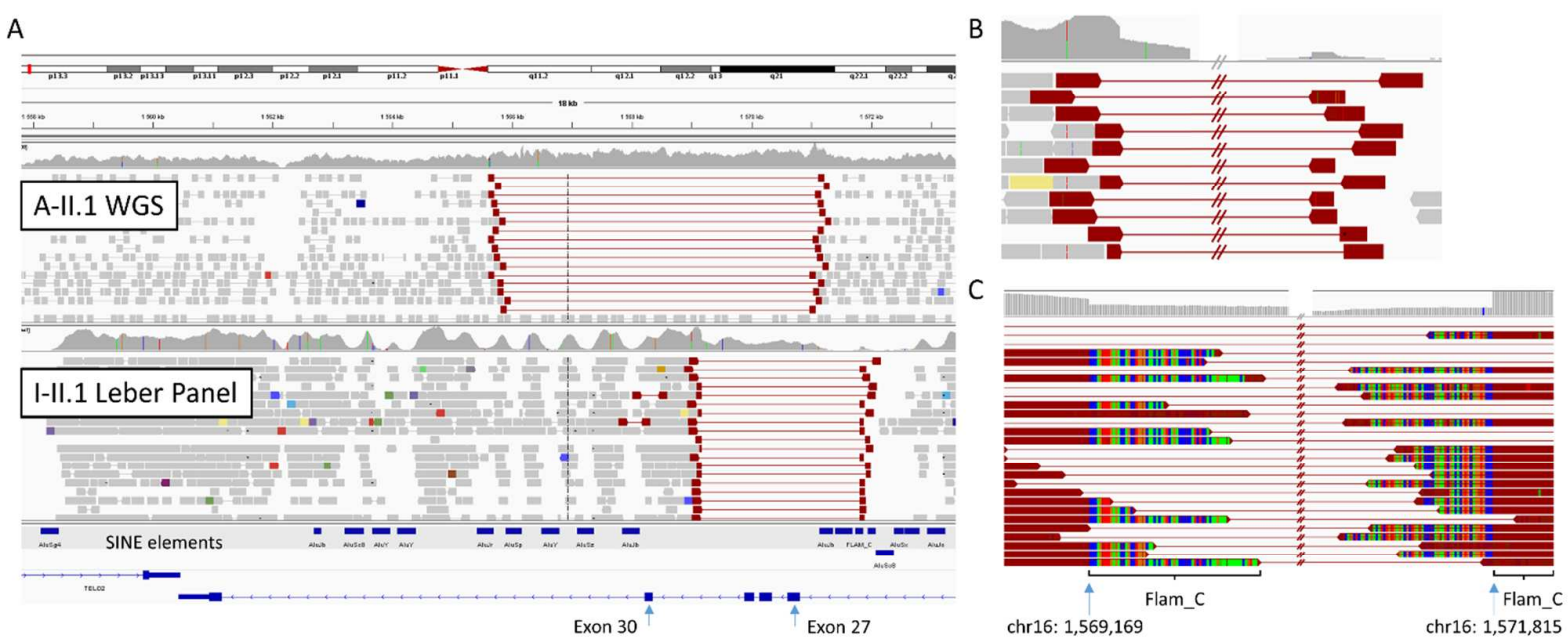

Figure S4. Next generation sequencing data for family A and I displayed around IFT140, in particular from exon 27 to exon 30 .

(A) Comparison between whole genome sequencing (WGS) from patient A-II.1 (tandem duplication carrier) and targeted exome sequencing using the full IFT140 gene as a target region from patient I-II.1 (deletion of exon 27 to 29). The reads are displayed as pairs and sorted according to their insert size using IGV (Thorvaldsdottir, et al., 2013). The two events do not share the same breakpoints.

(B) Highlight of the read pairs from patient I-II.1 at the breakpoint junctions showing the typical drawing (read pairs pointing at each other) for a genomic deletion.

(C) Highlight of the read pairs from patient I-II.1 at the breakpoints including soft clipped bases. The right breakpoint overlaps a SINE element from the Alu family (Flam_C) but not the left breakpoint. Analysis of the split reads that are misaligned allows us to define the exact position of the deletion (c.3454-1005_4040+737delinsCCC). 


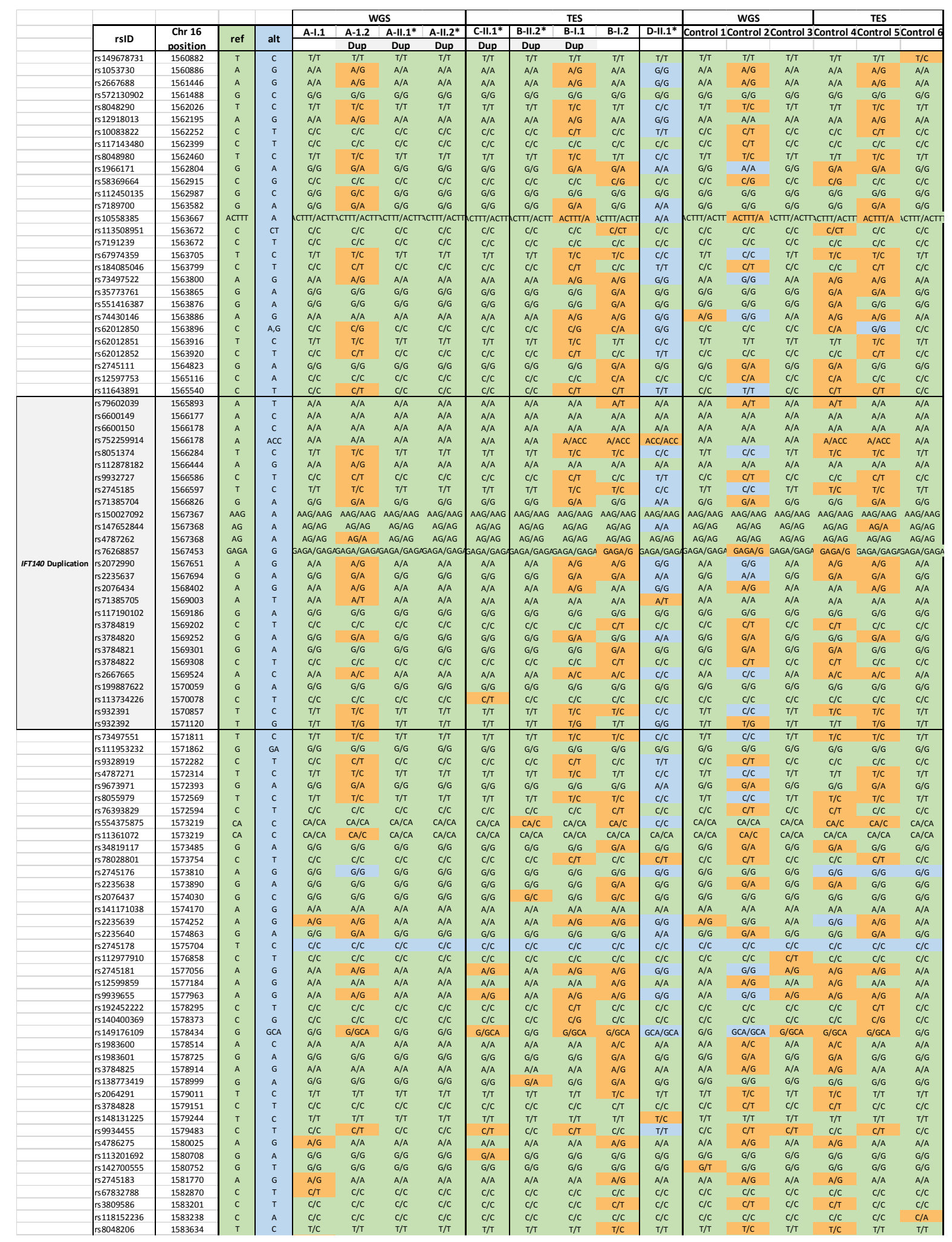




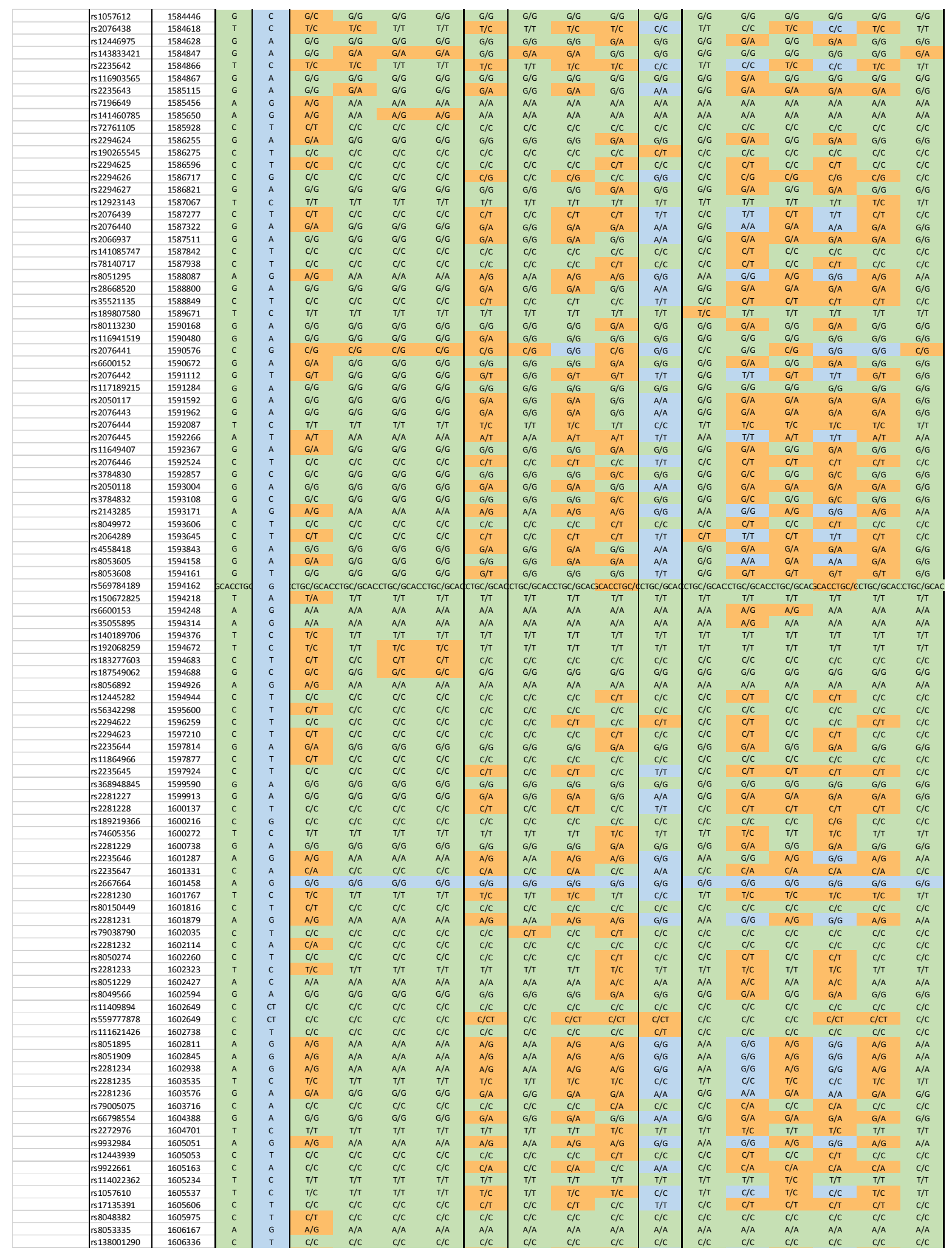




\begin{tabular}{|c|c|c|c|c|c|c|c|c|c|}
\hline |rs138001290 & 1606336 & c & T & $c / c$ & $c / c$ & $c / c$ & $c / c$ & $c / c$ & $c / c$ \\
\hline rs55817051 & 1606444 & A & $G$ & $\mathrm{~A} / \mathrm{G}$ & A/A & $\mathrm{A} / \mathrm{A}$ & $\mathrm{A} / \mathrm{A}$ & $\mathrm{A} / \mathrm{G}$ & $A / A$ \\
\hline 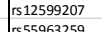 & $\begin{array}{l}1606445 \\
1106579\end{array}$ & A & ${ }^{G}$ & A/G & A/A & A/A & A/A & $A / G$ & $A / A$ \\
\hline 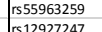 & $\begin{array}{l}1606479 \\
11606739\end{array}$ & c & $\begin{array}{l}T \\
G\end{array}$ & C/T & $\begin{array}{l}\mathrm{C} / \mathrm{C} \\
\mathrm{A} / \mathrm{A}\end{array}$ & $\begin{array}{l}c / C \\
A / A\end{array}$ & ${ }^{c / C}$ & $c / c$ & $c / c$ \\
\hline $\begin{array}{l}\mathrm{rr} 129272727 \\
\mathrm{r} 5112810668\end{array}$ & $\begin{array}{l}16066739 \\
1607113\end{array}$ & $\begin{array}{l}A \\
G C\end{array}$ & $\begin{array}{l}G \\
G\end{array}$ & $\begin{array}{l}A \mathrm{~A} / \mathrm{A} \\
\mathrm{GC/G}\end{array}$ & $\begin{array}{c}A A / A \\
G C / G C\end{array}$ & $\begin{array}{l}A / A \\
G C / G C\end{array}$ & $\begin{array}{l}\begin{array}{c}A / A \\
G C / G C\end{array} \\
\text {. }\end{array}$ & $\begin{array}{l}A / G \\
G C / G C\end{array}$ & $\begin{array}{c}A / A \\
G C / G C\end{array}$ \\
\hline 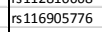 & 1607242 & c & $\mathrm{T}$ & $c / c$ & $c / c$ & $c / c$ & $c / c$ & $c / c$ & $c / c$ \\
\hline \begin{tabular}{|l|l|}
$\mathbf{r s} 1164292907$ \\
\end{tabular} & 1607284 & G & 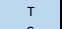 & G/G & G/G & G/G & G/6 & $G / G$ & G/G \\
\hline 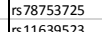 & $\begin{array}{l}1607286 \\
1107654\end{array}$ & ${ }^{G}$ & c & G/C & G/G & G/G & G/6 & $G / G$ & G/G \\
\hline 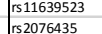 & $\begin{array}{l}16607564 \\
1607574\end{array}$ & $\begin{array}{l}T \\
c\end{array}$ & $\begin{array}{l}\mathrm{c} \\
\mathrm{T}\end{array}$ & $\begin{array}{l}T / T \\
C / T\end{array}$ & $\begin{array}{l}T / T \\
c / c\end{array}$ & $\begin{array}{l}\text { T/T } \\
c / c\end{array}$ & $\begin{array}{l}T / T \\
c / C\end{array}$ & $\begin{array}{l}T / T / T \\
C / T\end{array}$ & $\begin{array}{l}T / T \\
c / c\end{array}$ \\
\hline rs 2076436 & 1608082 & A & G & $\mathrm{A} / \mathrm{A}$ & $A / A$ & $A / A$ & $\mathrm{~A} / \mathrm{A}$ & $\mathrm{A} / \mathrm{G}$ & $\mathrm{A} / \mathrm{A}$ \\
\hline rs 2235641 & 1608177 & A & ${ }^{G}$ & $\mathrm{~A} / \mathrm{A}$ & A/A & $A / A$ & $\mathrm{~A} / \mathrm{A}$ & $A / G$ & $A / A$ \\
\hline ris12446290 & 1608364 & & A & $6 / 6$ & $G / 6$ & G/G & G/G & $6 / 6$ & $G / 6$ \\
\hline [r574821318 & 1608729 & G & A & G/G & G/G & $6 / 6$ & G/G & $6 / 6$ & G/G \\
\hline |r5540739250 & 1608904 & $c$ & $\mathrm{~T}^{\mathrm{T}}$ & $c / c$ & $c / c$ & $c / c$ & $c / c$ & $c / c$ & $c / c$ \\
\hline rrs56289115 & 1608934 & A & G & $\mathrm{A} / \mathrm{G}$ & A/A & $\mathrm{A} / \mathrm{A}$ & $\mathrm{A} / \mathrm{A}$ & $A / G$ & $\mathrm{~A} / \mathrm{A}$ \\
\hline rs 574381546 & 1609135 & $\begin{array}{l}T \\
\end{array}$ & c & $T / T$ & $T / T$ & $T / T$ & $T / T$ & $T / T$ & $T / T$ \\
\hline 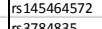 & 1609624 & c & A & $c / c$ & $c / c$ & $c / c$ & $c / c$ & & $c / c$ \\
\hline 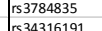 & $\begin{array}{l}1609843 \\
11509944\end{array}$ & $G$ & $\begin{array}{l}c \\
\text { c }\end{array}$ & G/G & G/G & G/6 & 6/6 & G/G & G/G \\
\hline \begin{tabular}{|l}
$\mathbf{r r s} 343361691$ \\
$\mathrm{rs} 37784836$
\end{tabular} & $\begin{array}{l}16099444 \\
1610176\end{array}$ & $\begin{array}{l}c \\
G\end{array}$ & ${ }_{A}^{T}$ & $\begin{array}{l}6 / C \\
G / G\end{array}$ & $\begin{array}{l}\text { /T } \\
G / 6\end{array}$ & $\begin{array}{l}6 / T \\
G / 6\end{array}$ & $\begin{array}{l}C / T \\
G / 6\end{array}$ & $\begin{array}{l}c / C \\
G / 6\end{array}$ & $\begin{array}{l}C / T \\
G / G\end{array}$ \\
\hline rs 15378483037 & 1610215 & c & G & $c / G$ & $c / c$ & $c / c$ & $c / c$ & c/c & $\mathrm{c} / \mathrm{c}$ \\
\hline rs 2003343 & 1610578 & G & A & G/G & G/G & $6 / 6$ & $6 / 6$ & $G / G$ & $6 / 6$ \\
\hline \begin{tabular}{|l}
$\mathbf{r s 1 0 1 0 1 6 4 9 9}$ \\
$\mathbf{r}$
\end{tabular} & $\begin{array}{l}1610885 \\
\end{array}$ & A & G & A/G & A/A & A/A & A/A & A/A & A/A \\
\hline 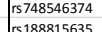 & $\begin{array}{l}1612145 \\
16122459\end{array}$ & ${ }_{\text {GT }}$ & ${ }_{\mathrm{G}}^{\mathrm{T}}$ & $\begin{array}{l}G T / G T \\
G C T\end{array}$ & GT/GT & GT/GT & GT/GT & GT/GT & $G T / G$ \\
\hline $\begin{array}{l}\mid r 5188815635 \\
\mathrm{rs} 37784838\end{array}$ & $\begin{array}{l}16124599 \\
1612498\end{array}$ & $\begin{array}{l}c \\
c\end{array}$ & $\begin{array}{l}T \\
G\end{array}$ & $\begin{array}{l}c / c \\
c / G\end{array}$ & $\begin{array}{l}c / c \\
c / c\end{array}$ & $\begin{array}{l}c / c \\
c / c\end{array}$ & $\begin{array}{l}c / c \\
c / c\end{array}$ & $\begin{array}{l}c / c \\
c / c\end{array}$ & $\begin{array}{l}c / c \\
c / c\end{array}$ \\
\hline rs 12935364 & 1613348 & A & G & $\mathrm{A} / \mathrm{G}$ & A/A & $A / A$ & $\mathrm{~A} / \mathrm{A}$ & $\mathrm{A} / \mathrm{A}$ & $A / A$ \\
\hline rrs12446060 & 1613365 & G & A & G/G & G/G & 6/6 & 6/6 & $6 / 6$ & $6 / 6$ \\
\hline 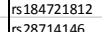 & $\begin{array}{l}1613428 \\
11613793\end{array}$ & T & c & $T / T$ & T/T & $T / \tau$ & $T / \tau$ & $T / T$ & $T / T$ \\
\hline 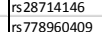 & $\begin{array}{l}1613793 \\
1614093\end{array}$ & A & c & $\begin{array}{l}\mathrm{A} / \mathrm{A} \\
\mathrm{G} / \mathrm{G}\end{array}$ & $\begin{array}{l}A / A \\
G / G\end{array}$ & $\begin{array}{l}A / A \\
G / G\end{array}$ & $\begin{array}{l}A / A \\
G / G\end{array}$ & $\begin{array}{l}A / C \\
G / G\end{array}$ & $\begin{array}{l}A / A \\
G / G\end{array}$ \\
\hline 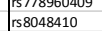 & $\begin{array}{l}1614093 \\
1614097\end{array}$ & $\begin{array}{l}G \\
A\end{array}$ & $\begin{array}{l}A \\
G\end{array}$ & $\begin{array}{l}\mathrm{A} / \mathrm{G} \\
\mathrm{A} / \mathrm{G}\end{array}$ & $A / A$ & 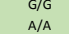 & A/A & $\begin{array}{l}G / G \\
A / G\end{array}$ & $\begin{array}{l}G / 6 \\
A / A\end{array}$ \\
\hline rs 1512488883 & 1614240 & c & G & $c / c$ & $c / c$ & $c / c$ & $c / c$ & $c / c$ & $\mathrm{clc}$ \\
\hline rs517135407 & 1615189 & G & A & G/A & G/G & $6 / 6$ & $6 / 6$ & $6 / 6$ & $6 / 6$ \\
\hline |rs511648609 & 1616201 & & ${ }^{\top}$ & & $c / c$ & $c / c$ & & $c / c$ & $c / c$ \\
\hline rs 116908844 & 1616528 & $T$ & A & $T / T$ & $T / T$ & $T / T$ & $T / T$ & $c / c$ & $c / c$ \\
\hline rss11648819 & 1616663 & c & $\mathrm{T}^{\mathrm{S}}$ & $c / c$ & $c / c$ & $c / c$ & $c / c$ & $c / c$ & $c / c$ \\
\hline rs80599442 & 1616722 & G & A & $G / G$ & G/G & G/G & G/G & G/G & $G / 6$ \\
\hline |rs77486198 & 1616838 & c & $\mathrm{T}$ & $c / c$ & $c / c$ & $c / c$ & $c / c$ & $c / c$ & $c / c$ \\
\hline 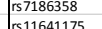 & $\begin{array}{l}1617688 \\
1168007\end{array}$ & c & ${ }^{G}$ & c/G & $c / c$ & $c / c$ & $c / c$ & $c / c$ & $c / c$ \\
\hline 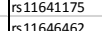 & $\begin{array}{l}1618007 \\
16181812\end{array}$ & $\begin{array}{l}\text { C } \\
\text { A }\end{array}$ & $\begin{array}{l}\text { A } \\
\text { C }\end{array}$ & $\begin{array}{l}\mathrm{C} / \mathrm{C} \\
\mathrm{A} / \mathrm{A}\end{array}$ & $\begin{array}{l}\text { C/C } \\
\text { A/A }\end{array}$ & $\begin{array}{c}c / C \\
A / A\end{array}$ & $\begin{array}{c}C / C \\
A / A\end{array}$ & $\begin{array}{l}c / C \\
A / A\end{array}$ & $\begin{array}{l}c / c \\
A / A\end{array}$ \\
\hline 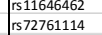 & $\begin{array}{l}16181112 \\
1618995\end{array}$ & $\begin{array}{l}A \\
T\end{array}$ & $\begin{array}{l}c \\
c\end{array}$ & $\begin{array}{l}\text { A A } \\
T / T\end{array}$ & $\begin{array}{l}\text { A } \\
T / T\end{array}$ & $\begin{array}{l}\text { A/A } \\
T / T\end{array}$ & $\begin{array}{l}\text { A/A } \\
T / T\end{array}$ & $\begin{array}{l}A / A \\
T / T\end{array}$ & $\begin{array}{l}A / A \\
T / T\end{array}$ \\
\hline rs 181807594099 & 1619066 & c & $\mathrm{T}$ & $\mathrm{C} / \mathrm{T}$ & $c / c$ & $c / T$ & $C / T$ & $c / c$ & $c / c$ \\
\hline rs9927187 & 1619074 & c & $\mathrm{T}$ & $C / T$ & $c / c$ & $c / c$ & $c / c$ & $c / c$ & $c / c$ \\
\hline rs99398999 & 1619082 & T & c & $T / C$ & $T / T$ & $T / T$ & T/T & $T / T$ & $T / T$ \\
\hline rs99927511 & 1619431 & c & T & $C / T$ & $c / c$ & $c / c$ & $c / c$ & $c / c$ & $c / c$ \\
\hline rs99927529 & 1619488 & c & $\mathrm{T}^{\mathrm{T}}$ & $C / T$ & $c / c$ & $c / c$ & $c / c$ & $\mathrm{C} / \mathrm{T}$ & $c / c$ \\
\hline 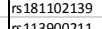 & $\begin{array}{l}1619703 \\
11619758\end{array}$ & \begin{tabular}{|l|l|} 
\\
\end{tabular} & 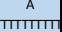 & $\begin{array}{l}\mathrm{T} / \mathrm{T} / \mathrm{T} \\
\mathrm{TTHT/ATII}\end{array}$ & T/T & $T / T$ & ${ }^{T / T}$ & $T / T$ & ${ }^{T / T}$ \\
\hline 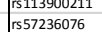 & 1619758 & & AT & $A / A T$ & $\mathrm{~A} / \mathrm{A}$ & $\mathrm{A} / \mathrm{A}$ & $\mathrm{A} / \mathrm{A}$ & $\mathrm{A} / \mathrm{A}$ & $\mathrm{A} / \mathrm{A}$ \\
\hline rrs551270839 & 1619758 & A & AT,ATT & $\mathrm{A} / \mathrm{A}$ & $\mathrm{A} / \mathrm{A}$ & $A / A$ & $A / A$ & $\mathrm{~A} / \mathrm{A}$ & $\mathrm{A} / \mathrm{A}$ \\
\hline rss117401189 & 1619761 & $\mathrm{~T}$ & & $T / T$ & $T / T$ & $T / T$ & $T / T$ & $T / T$ & $\mathrm{~T} / \mathrm{T}$ \\
\hline r r 14141314600 & 1619825 & $G$ & c & $G / G$ & $G / G$ & G/G & $6 / 6$ & $6 / 6$ & $6 / 6$ \\
\hline |rs7200291 & 1619896 & A & $\begin{array}{l}\mathrm{T} \\
\end{array}$ & $A / T$ & A/A & $A / A$ & $A / A$ & $\mathrm{~A} / \mathrm{A}$ & $\mathrm{A} / \mathrm{A}$ \\
\hline 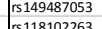 & $\begin{array}{l}1620307 \\
1120024\end{array}$ & c & T & $c / c$ & $C / T$ & $c / c$ & $c / c$ & $c / c$ & $c / c$ \\
\hline 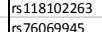 & $\begin{array}{l}1620424 \\
11200468\end{array}$ & $\begin{array}{l}G \\
G\end{array}$ & $\begin{array}{l}c \\
c \\
c\end{array}$ & $\begin{array}{l}G / G \\
G / G\end{array}$ & $\begin{array}{l}G / G \\
G / G\end{array}$ & $\begin{array}{l}G / 6 \\
G / G\end{array}$ & $\begin{array}{l}6 / 6 \\
G / 6\end{array}$ & $G / G$ & $\begin{array}{l}G / 6 \\
G / 6\end{array}$ \\
\hline \begin{tabular}{|l}
5576069945 \\
$\mathrm{r} 572769116$
\end{tabular} & $\begin{array}{l}16200468 \\
1620550\end{array}$ & $\begin{array}{l}G \\
c\end{array}$ & $\begin{array}{l}\mathrm{c} \\
\mathrm{T}\end{array}$ & $\begin{array}{l}\text { G/G } \\
C / T\end{array}$ & $\begin{array}{l}\text { /G } \\
c / c\end{array}$ & $\begin{array}{l}6 / 6 \\
C / C\end{array}$ & $\begin{array}{l}6 / 6 \\
c / C\end{array}$ & $\begin{array}{l}\text { G/G } \\
C / C\end{array}$ & $\begin{array}{l}6 / 6 \\
C / C\end{array}$ \\
\hline 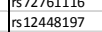 & $\begin{array}{l}1025350 \\
1621119\end{array}$ & $G$ & c & G/G & $\mathrm{G} / \mathrm{G}$ & $6 / 6$ & $6 / 6$ & $\begin{array}{l}C / C \\
G / G\end{array}$ & $\begin{array}{l}C / C \\
G / 6\end{array}$ \\
\hline rs 1998826737 & 1621495 & c & $\mathrm{T}$ & $c / c$ & $c / c$ & $c / c$ & $c / c$ & $c / c$ & $\mathrm{C} / \mathrm{T}$ \\
\hline \begin{tabular}{|l|l} 
rs 72481007 \\
\end{tabular} & 1621702 & c & $T$ & $c / c$ & $c / c$ & $c / c$ & $\mathrm{c} / \mathrm{C}$ & $\mathrm{c} / \mathrm{C}$ & $\mathrm{c} / \mathrm{C}$ \\
\hline r 1559963862 & 1621967 & T & c & $T / T$ & $T / T$ & $T / T$ & $T / T$ & $T / T$ & $T / T$ \\
\hline rs 1517135411 & 1622008 & A & G & $\mathrm{A} / \mathrm{G}$ & $\mathrm{A} / \mathrm{A}$ & $\mathrm{A} / \mathrm{A}$ & $\mathrm{A} / \mathrm{A}$ & $\mathrm{A} / \mathrm{A}$ & $A / A$ \\
\hline |rs58856196 & 1622092 & c & $\mathrm{T}_{\mathrm{S}}$ & $C / T$ & $c / c$ & $c / c$ & $c / c$ & $c / c$ & $c / c$ \\
\hline r 1558334533 & 1622108 & G & A & G/A & G/G & $6 / 6$ & $6 / 6$ & G/G & $6 / 6$ \\
\hline 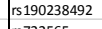 & 1622539 & c & $\begin{array}{l}\mathrm{T} \\
\mathrm{s}\end{array}$ & $c / c$ & $\mathrm{C} / \mathrm{T}$ & $c / T$ & $c / T$ & $c / c$ & $c / T$ \\
\hline 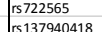 & $\begin{array}{l}1623251 \\
1\end{array}$ & \begin{tabular}{|c|}
$G$ \\
СTGGAT
\end{tabular} & A & \begin{tabular}{|l} 
G/A \\
СТGAT/C
\end{tabular} & $\begin{array}{c}\text { G/G } \\
\text { JTAT/CTTG }\end{array}$ & $\begin{array}{l}\text { G/G } \\
\text { ГАП/СТTC }\end{array}$ & $\begin{array}{c}\text { G/G } \\
\text { БТAT/CTTG }\end{array}$ & $\begin{array}{l}\text { G/G } \\
\text { :ATTCTTG }\end{array}$ & $\begin{array}{l}\text { GAT/G } \\
\text { ТTTGG }\end{array}$ \\
\hline $\mid \begin{array}{l}\mathbf{r r} 1379490418 \\
\mathrm{r} 5779600138\end{array}$ & & $\begin{array}{c}c \text { chGGATI } \\
c\end{array}$ & $\begin{array}{l}c \\
\text { T }\end{array}$ & $\begin{array}{l}C T G G A T / C \\
C / C\end{array}$ & $\begin{array}{l}\text { STATT/CTG } \\
C / C\end{array}$ & & $\begin{array}{l}\text { ITATR/CTC } \\
C / C\end{array}$ & $\begin{array}{l}\text { TAAT/CTEG } \\
\text { C/C }\end{array}$ & TAAT/CTG \\
\hline 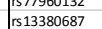 & $\begin{array}{l}10263538 \\
1623852\end{array}$ & ${ }_{A}^{C}$ & G & $A / G$ & $A / A$ & $A / A$ & $\mathrm{~A} / \mathrm{A}$ & $\mathrm{A} / \mathrm{A}$ & $\mathrm{A} / \mathrm{A}$ \\
\hline rs 1470 & 1624106 & T & c & $T / C$ & 年 & $T / T$ & 11 & $T / T$ & $T / T$ \\
\hline & 1624142 & $T$ & $c$ & $T / C$ & $T / T$ & T/T & $T / T$ & $T / T$ & T/ \\
\hline rs12596975 & 1624493 & G & A & G/A & G/6 & G/G & $6 / 6$ & $6 / 6$ & $G / 6$ \\
\hline rs 112369751 & 1624528 & & & & & & & & $\mathrm{c} / \mathrm{c}$ \\
\hline 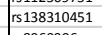 & 1624771 & сcсct & c & сcсct/c & :CCCT/CCCC & E.ccct/ccce & $\mathrm{Eccct//Cccc}$ & $\mathrm{cCT} / \mathrm{Cccc}$ & $\mathrm{ccct} / \mathrm{ccc}$ \\
\hline rs 58060 & 1624784 & 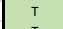 & G & $T / T$ & $T / T$ & $T / T$ & $T / T$ & $T / 6$ & $T / T$ \\
\hline | 1500042127 & 1625244 & $\begin{array}{l}T \\
T\end{array}$ & 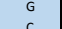 & T/T & 酸 & $T_{-T / T}^{T / T}$ & Th & $T / G$ & $\mathrm{~T} / \mathrm{T}$ \\
\hline rs513380456 & 1625890 & T & c & $\mathrm{T} / \mathrm{C}$ & T/T & $T / \tau$ & & $T / T$ & $T / T$ \\
\hline $\mid \begin{array}{l}r 5111924003 \\
r_{51512443870}\end{array}$ & $\begin{array}{l}162626058 \\
1626079\end{array}$ & $\begin{array}{l}G \\
A\end{array}$ & $\begin{array}{l}A \\
G\end{array}$ & $\begin{array}{l}\text { G/A } \\
A / G /\end{array}$ & G/G & G/G & G/G & $\begin{array}{l}G / 6 \\
A / A\end{array}$ & G/6 \\
\hline $\mid \begin{array}{l}1512445870 \\
r_{53535262072}\end{array}$ & $\begin{array}{l}10260 / 9 \\
1626287\end{array}$ & $\begin{array}{l}{ }^{A} \\
T\end{array}$ & TA & $\begin{array}{l}\text { T/G } \\
T / T A\end{array}$ & Th & $\begin{array}{l}\text { A/A } \\
T \text { T/T }\end{array}$ & $\begin{array}{l}\text { Th/ } \\
T / T\end{array}$ & $\begin{array}{l}\text { A/A } \\
T / T\end{array}$ & $\begin{array}{l}A / A \\
T / T\end{array}$ \\
\hline |rs512 & 1626318 & 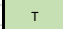 & m & $T / C$ & $T / T$ & $T / T$ & $T / T$ & $T / T$ & $T / T$ \\
\hline & 1626592 & 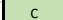 & CA & $c / c$ & $c / c$ & $c / c$ & $c / c$ & C/CA & $C / C A$ \\
\hline |r559783459 & 1626607 & 6 & 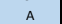 & $c / c$ & $c / c$ & $c / c$ & $c / c$ & $c / c$ & $c / c$ \\
\hline |r5148769752 & 1626652 & TCAGA & $T$ & $\angle A G A / T C A G$ & CAGA/TCAG & AGA/TCAC, & CAAGA/TCAC & AGA/TC, & AGA/TCAG \\
\hline rs 117 & 1626702 & 6 & A & $G / G$ & $G / G$ & $6 / 6$ & $6 / 6$ & $\mathrm{G} / \mathrm{A}$ & $G / G$ \\
\hline \begin{tabular}{|l|} 
rs881821 \\
\end{tabular} & 1626705 & T & A & T/A & $T / T$ & $T / T$ & $T / T$ & $T / T$ & $T / T$ \\
\hline 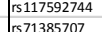 & $\begin{array}{l}1626884 \\
1627726\end{array}$ & ${ }_{T}^{G}$ & $\begin{array}{l}c \\
c\end{array}$ & $\begin{array}{l}G / G \\
T / T\end{array}$ & $\begin{array}{l}\mathrm{G} / \mathrm{G} \\
\mathrm{T} / \mathrm{T}\end{array}$ & $\begin{array}{l}\text { G/G } \\
T / T\end{array}$ & $\begin{array}{l}\text { G/G } \\
T / T\end{array}$ & $\begin{array}{c}G / C \\
T / T\end{array}$ & $\begin{array}{l}G / 6 \\
T / T\end{array}$ \\
\hline 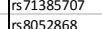 & $\begin{array}{l}1627726 \\
16257508\end{array}$ & T & c & $\begin{array}{l}T / T / T \\
A / G\end{array}$ & 政 & $\begin{array}{l}T / T \\
A / A\end{array}$ & $\begin{array}{l}T / T \\
A / A\end{array}$ & $T^{T / T}$ & $T / T$ \\
\hline 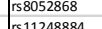 & $\begin{array}{l}1627508 \\
16277618\end{array}$ & & A & $\begin{array}{l}A / G \\
G / G\end{array}$ & $\begin{array}{l}\text { /A } \\
\text { G/G }\end{array}$ & 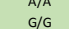 & $\begin{array}{l}A / A \\
G / G\end{array}$ & $\begin{array}{l}A / A \\
G / G\end{array}$ & $\begin{array}{l}A / A \\
G / G\end{array}$ \\
\hline 84 & $\begin{array}{l}1627 \\
1627\end{array}$ & & T & $\begin{array}{l}\text { G/G } \\
C / T\end{array}$ & $c / c$ & c/c & $c / c$ & $\begin{array}{l}G / 6 \\
c / c\end{array}$ & ${ }_{c /}^{G /}$ \\
\hline 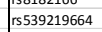 & 1627856 & TA & $T$ & $\mathrm{TA} / \mathrm{TA}$ & TA/TA & TA/TA & TA/TA & TA/T & TA/TA \\
\hline & & & CAA & C/CAA & $c / c$ & & $\mathrm{c} / \mathrm{c}$ & 4 & $c / c$ \\
\hline rs 11644 & 1628225 & T & s & $T$ & 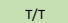 & $T / T$ & 4 & 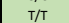 & $T / T$ \\
\hline rss11647721 & 1628295 & & A & $G / G$ & 6/6 & $6 / 6$ & $6 / 6$ & $6 / 6$ & $6 / 6$ \\
\hline rs36091619 & 1628579 & TA & T & TA/TA & TA/TA & TA/TA & TA/TA & $\mathrm{TA} / \mathrm{TA}$ & $\mathrm{TA} / \mathrm{TA}$ \\
\hline
\end{tabular}




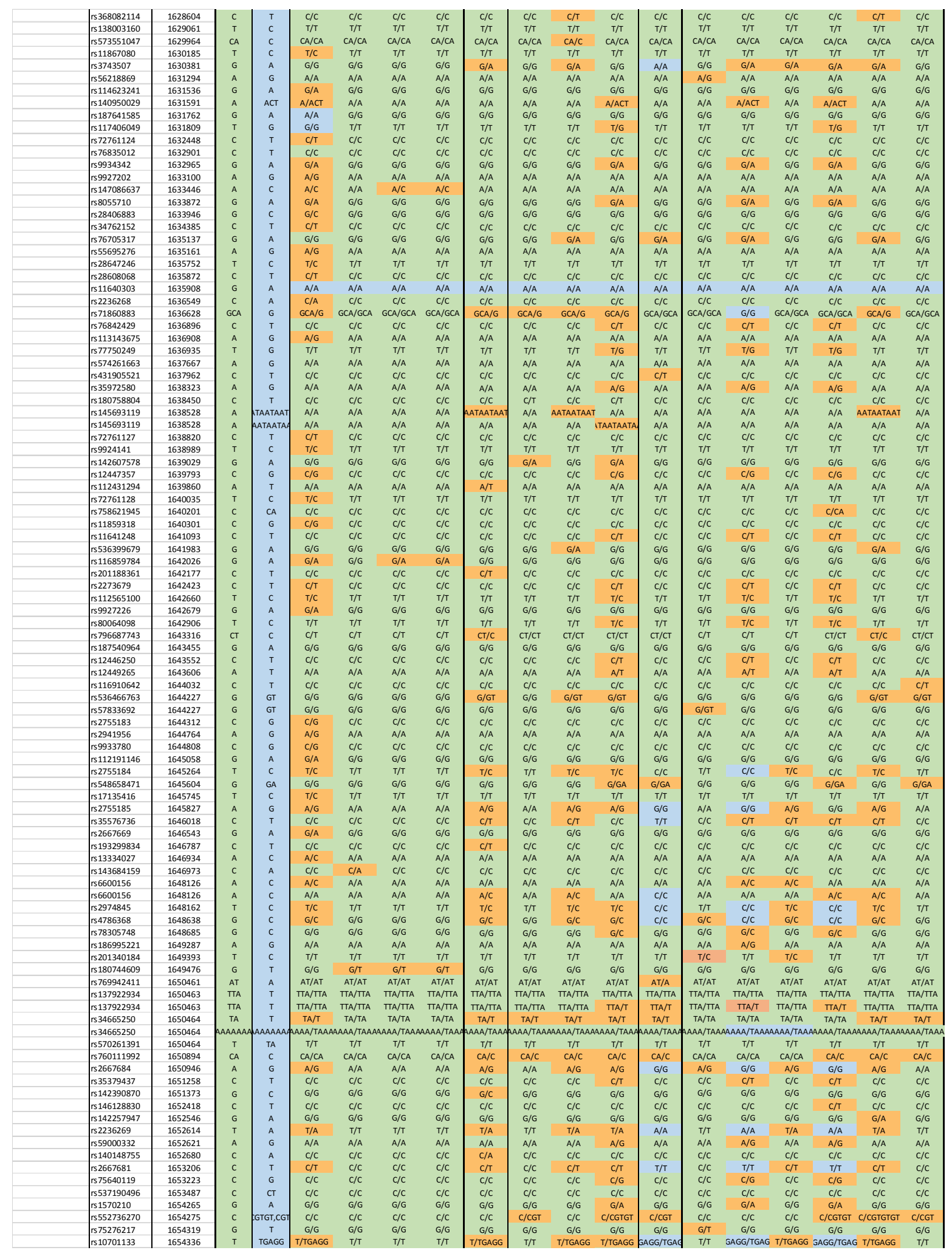




\begin{tabular}{|c|c|c|c|c|c|c|c|c|c|c|c|c|c|c|c|c|c|c|}
\hline |rs138669173 & 1654525 & c & G & $c / c$ & $c / c$ & $c / C$ & $c / c$ & $c / c$ & $c / c$ & $C / G$ & $c / c$ & $c / c$ & $c / c$ & $c / c$ & $c / c$ & $c / c$ & $c / G$ & $c / c$ \\
\hline rs7197288 & 1654753 & c & A & $\mathrm{C} / \mathrm{A}$ & $c / c$ & $c / c$ & $c / c$ & $\mathrm{C} / \mathrm{A}$ & $c / c$ & $C / A$ & $\mathrm{C} / \mathrm{A}$ & $A / A$ & $c / c$ & A/A & $\mathrm{C} / \mathrm{A}$ & A/A & $C / A$ & $c / c$ \\
\hline Irs2667679 & 1654946 & G & A & G/A & G/G & G/G & G/G & G/A & G/G & G/A & G/G & $A / A$ & G/G & G/A & G/A & G/A & $G / A$ & G/G \\
\hline rs56359342 & 1654948 & G & A & G/A & G/G & G/G & G/G & $G / A$ & G/G & G/A & G/G & $A / A$ & G/G & G/A & G/A & G/A & G/A & G/G \\
\hline rs 117745556 & 1655073 & $T$ & c & $T / T$ & $T / T$ & $T / T$ & $T / T$ & $T / T$ & $T / T$ & $T / T$ & $T / C$ & $T / T$ & $T / T$ & $T / C$ & $T / T$ & $T / C$ & $T / T$ & $T / T$ \\
\hline rs 35220693 & 1655439 & c & $\mathrm{T}$ & $c / c$ & $c / c$ & $c / c$ & $c / c$ & $c / c$ & $c / c$ & $c / c$ & $\mathrm{C} / \mathrm{T}$ & $c / c$ & $c / c$ & $\mathrm{C} / \mathrm{T}$ & $c / c$ & $\mathrm{C} / \mathrm{T}$ & $c / c$ & $\mathrm{c} / \mathrm{c}$ \\
\hline rs6600157 & 1656321 & G & A & G/A & G/G & G/G & G/G & G/G & G/G & G/G & G/G & G/G & G/G & G/G & G/G & G/G & G/G & G/G \\
\hline is 142169797 & 1656564 & c & 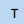 & $c / c$ & $c / c$ & $c / c$ & $c / c$ & $c / c$ & $c / c$ & $c / c$ & $c / c$ & $c / c$ & $c / c$ & $c / c$ & $c / c$ & $c / c$ & $c / c$ & $c / c$ \\
\hline Irs2859310 & 1656765 & A & G & $\mathrm{A} / \mathrm{G}$ & A/A & A/A & $A / A$ & $\mathrm{~A} / \mathrm{G}$ & A/A & $A / G$ & $A / G$ & G/G & $A / A$ & G/G & $A / G$ & G/G & $\mathrm{A} / \mathrm{G}$ & $A / A$ \\
\hline Is 542474562 & 1656927 & GCACA & G & $\mathrm{CACA} / \mathrm{GCAC}$ & CACA/GCAC & CACA/GCAC & CACA/GCA & $\mathrm{CACA} / \mathrm{GCA}$ & $\mathrm{CAA} / \mathrm{GCAC}$ & $\mathrm{CACA} / \mathrm{GCA}$ & CACA/GCAD & $\mathrm{CA} / \mathrm{GCAC}$ & $C A / G C A C$ & CACA/GCAC & CACA/GCAC & CACA/GCAC & CACA/GCAC & GCACA/G \\
\hline rs7192480 & 1657012 & c & $\mathrm{T}$ & $\mathrm{c} / \mathrm{c}$ & $c / c$ & $\mathrm{c} / \mathrm{c}$ & $\mathrm{c} / \mathrm{C}$ & $\mathrm{C} / \mathrm{T}$ & $\mathrm{c} / \mathrm{c}$ & $\mathrm{C} / \mathrm{T}$ & $\mathrm{c} / \mathrm{c}$ & $T / T$ & $\mathrm{c} / \mathrm{C}$ & $\mathrm{C} / \mathrm{T}$ & $\mathrm{C} / \mathrm{T}$ & $\mathrm{C} / \mathrm{T}$ & $\mathrm{C} / \mathrm{T}$ & $\mathrm{c} / \mathrm{C}$ \\
\hline is 349935994 & 1657034 & САT & c & САТ $/ \mathrm{C}$ & CAT/CAT & СAT/CAT & САT/CAT & САT/CAT & CAT/CAT & CAT/CAT & CAT/CAT & СAT/CAT & CAT/CAT & CAT/CAT & CAT/CAT & CAT/CAT & CAT/CAT & САT/CAT \\
\hline rs 1894649 & 1657284 & c & G & $c / G$ & $c / c$ & $c / c$ & $c / c$ & $c / G$ & $c / c$ & $c / G$ & $c / G$ & G/G & $c / c$ & G/G & $c / G$ & G/G & $c / G$ & $c / c$ \\
\hline rs 743963 & 1657350 & A & $\mathrm{T}$ & $A / T$ & $A / A$ & $A / A$ & $A / A$ & $\mathrm{~A} / \mathrm{T}$ & $A / A$ & $\mathrm{~A} / \mathrm{T}$ & $A / A$ & $T / T$ & $A / A$ & $\mathrm{~A} / \mathrm{T}$ & $\mathrm{A} / \mathrm{T}$ & $\mathrm{A} / \mathrm{T}$ & $\mathrm{A} / \mathrm{T}$ & A/A \\
\hline Irs 3784840 & 1657754 & c & T & $c / c$ & $c / c$ & $c / c$ & $c / c$ & $C / \mathrm{T}$ & $c / c$ & $C / \mathrm{T}$ & $c / c$ & $T / T$ & $c / c$ & $\mathrm{C} / \mathrm{T}$ & $C / T$ & $C / T$ & $C / T$ & $c / c$ \\
\hline Irs743964 & 1657853 & c & T & $c / c$ & $c / c$ & $c / c$ & $c / c$ & $c / c$ & $c / c$ & $c / c$ & $C / \mathrm{T}$ & $c / c$ & $c / c$ & $C / \mathrm{T}$ & $c / c$ & $C / T$ & $c / c$ & $c / c$ \\
\hline rs 763152 & 1658056 & T & c & $T / C$ & $T / T$ & $T / T$ & $T / T$ & $T / C$ & $T / T$ & $T / C$ & $T / C$ & $\mathrm{c} / \mathrm{c}$ & $T / T$ & $c / c$ & $T / C$ & $c / c$ & $T / C$ & $T / T$ \\
\hline is 763153 & 1658086 & G & c & $\mathrm{G} / \mathrm{G}$ & $\mathrm{G} / \mathrm{G}$ & $\mathrm{G} / \mathrm{G}$ & $\mathrm{G} / \mathrm{G}$ & G/G & G/G & G/G & $\mathrm{G} / \mathrm{C}$ & $\mathrm{G} / \mathrm{G}$ & $\mathrm{G} / \mathrm{G}$ & $G / C$ & $\mathrm{G} / \mathrm{G}$ & $G / C$ & $\mathrm{G} / \mathrm{G}$ & G/G \\
\hline rs 35888283 & 1658101 & TAG & T & $\mathrm{TAG} / \mathrm{T}$ & TAG/TAG & TAG/TAG & TAG/TAG & $\mathrm{TAG} / \mathrm{T}$ & TAG/TAG & TAG/T & TAG/TAG & $T / T$ & TAG/TAG & $\mathrm{TAG} / \mathrm{T}$ & $\mathrm{TAG} / \mathrm{T}$ & $\mathrm{TAG} / \mathrm{T}$ & $\mathrm{TAG} / \mathrm{T}$ & TAG/TAG \\
\hline rs & 1658154 & c & G & $\mathrm{C} / \mathrm{G}$ & $c / c$ & c/c & $c / c$ & $C / G$ & C/C & $C / G$ & $\mathrm{C} / \mathrm{G}$ & G/G & $\mathrm{c} / \mathrm{c}$ & $\mathrm{G} / \mathrm{G}$ & $\mathrm{C} / \mathrm{G}$ & $\mathrm{G} / \mathrm{G}$ & $c / 6$ & $\mathrm{c} / \mathrm{C}$ \\
\hline rs 115729443 & 1658454 & c & T & $c / c$ & $c / c$ & $c / c$ & $c / c$ & $c / c$ & $c / c$ & $c / c$ & $C / T$ & $c / c$ & $c / c$ & $C / T$ & $c / c$ & $C / T$ & $c / c$ & $c / c$ \\
\hline rs 11438070 & 1658632 & c & CA & $c / c$ & $c / c$ & $c / c$ & $c / c$ & $c / c$ & $c / c$ & $c / c$ & c/c & $\mathrm{c} / \mathrm{c}$ & $\mathrm{c} / \mathrm{c}$ & $c / c$ & $c / c$ & $c / c$ & c/c & $\mathrm{c} / \mathrm{c}$ \\
\hline rs 28519681 & 1659128 & T & c & $T / C$ & $T / T$ & $T / T$ & $T / T$ & $T / C$ & $T / T$ & $T / C$ & $T / C$ & $c / c$ & $T / T$ & $c / c$ & $T / C$ & $c / c$ & $T / C$ & $T / T$ \\
\hline rs 28633318 & 1659723 & T & G & $T / G$ & $T / T$ & $T / T$ & $T / T$ & $T / T$ & $T / T$ & $T / T$ & $T / T$ & $T / T$ & $T / T$ & $T / T$ & $T / T$ & $T / T$ & $T / T$ & $T / T$ \\
\hline Is 1057983 & 1660274 & A & G & $A / G$ & A/A & A/A & A/A & $A / G$ & $A / A$ & $A / G$ & $A / G$ & G/G & $A / A$ & G/G & $A / G$ & G/G & $A / G$ & $A / A$ \\
\hline rs 150781872 & 1661491 & c & $C A$ & $c / c$ & $c / c$ & c/c & $c / c$ & $c / c$ & $c / c$ & $c / c$ & $c / c$ & $c / c$ & $c / c$ & $c / c$ & $c / c$ & $c / c$ & $c / c$ & $c / c$ \\
\hline rs 2859314 & 1661701 & A & G & $A / G$ & $\mathrm{~A} / \mathrm{A}$ & $A / A$ & $A / A$ & $\mathrm{~A} / \mathrm{A}$ & A/A & $A / G$ & $A / G$ & $A / G$ & $\mathrm{~A} / \mathrm{A}$ & $\mathrm{G} / \mathrm{G}$ & $A / A$ & $A / G$ & $A / G$ & $A / A$ \\
\hline rs 553272330 & 1661814 & CA & c & $\mathrm{CA} / \mathrm{CA}$ & $\mathrm{CA} / \mathrm{CA}$ & $\mathrm{CA} / \mathrm{CA}$ & $\mathrm{CA} / \mathrm{CA}$ & $\mathrm{CA} / \mathrm{CA}$ & $\mathrm{CA} / \mathrm{C}$ & $\mathrm{CA} / \mathrm{C}$ & $C A / C$ & $\mathrm{CA} / \mathrm{C}$ & $\mathrm{CA} / \mathrm{CA}$ & CA/CA & $\mathrm{CA} / \mathrm{CA}$ & $\mathrm{CA} / \mathrm{C}$ & CA/CA & $\mathrm{CA} / \mathrm{C}$ \\
\hline
\end{tabular}

Table S6. Haplotype analysis for $\sim 100 \mathrm{~kb}$ around IFT140 on chromosome 16.

SNP analysis at the IFT140 locus for carrier individuals of the tandem duplication and in controls sequenced either by WGS or Target Exome Sequencing (TES, by the Leber panel which include the full IFT140 gene). In total, 6 carrier individuals from 3 families were analysed (family A, B and C) and indicated. Affected patients are depicted with an "**". Six control samples are also shown. For each individual, SNP detected in IFT140 were extracted and listed. Homozygous SNP are shown in green (reference allele) or in blue (alternative allele) and heterozygous SNP in orange. The duplication region is highlighted in grey. 


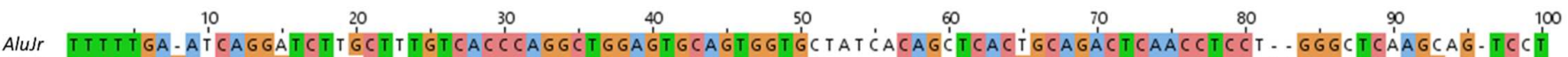
Alulb TTTTTGAGA-CAGGGTCTCACTCTGTCCCCCAGGCTGGAGTGCAGTGGTG....... CAG. TCACGGCAGCCTCCACCTCCCCAGGG-TC-AGGTGATCTT
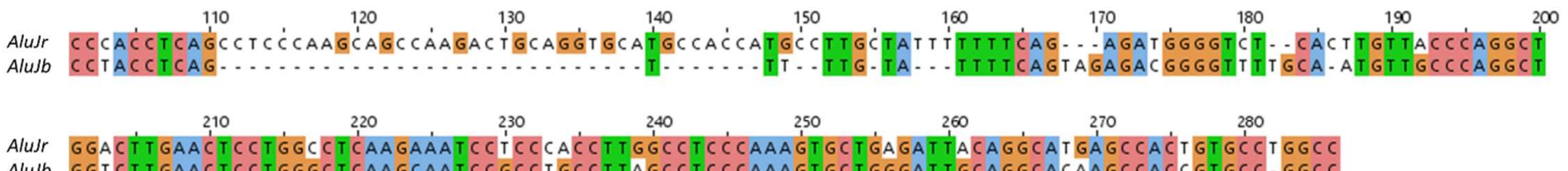

AluJb GGTCT TGAACTCCTGGGCTCAAGCAATCCGCCTGCCT TAGCCTCCCAAAGT GCT GGGATTGCAGGCACAAGCCACCGTGCC. GGCC

Figure S5 AluJb and AluJr alignment

AluJb and AluJr sequences were extracted from IGV (Thorvaldsdottir, et al., 2013) at the breakpoints of the tandem duplications. Pairwise alignment of the nucleotide sequences and percent identity has been computed using Jalview (Waterhouse, et al., 2009). 


\begin{tabular}{|c|c|c|c|c|}
\hline Technique & Individuals & CANOES & Pindel & CNVnator \\
\hline Ciliome panel & D-II.1 & DUP, intron26-intron30 & 67 DEL, 13 INV, 35 SI & NA \\
\hline Ciliome panel & K-II.2 & $\begin{array}{c}2 \text { DEL, 3DUP } \\
\text { (DUP, intron27-exon31) }\end{array}$ & 36 DEL, 1 INV, 6 SI, 1 TD & NA \\
\hline Leber panel & B-I.1 & DUP, intron26-intron30 & $\begin{array}{c}\text { DUP, intron26-intron30 } \\
\text { (675 DEL, } 70 \mathrm{INV}, 233 \mathrm{SI}, 5 \mathrm{TD})\end{array}$ & NA \\
\hline Leber panel & B-I.2 & 0 & (688 DEL, 62 INV, 211 SI, 2 TD) & NA \\
\hline Leber panel & B-II.1 & DUP, intron26-intron30 & $\begin{array}{c}\text { DUP, intron26-intron30 } \\
\text { (595 DEL, } 55 \text { INV, } 193 \text { SI, } 2 \text { TD) }\end{array}$ & NA \\
\hline Leber panel & C-II.1 & DUP, intron26-intron30 & $\begin{array}{c}\text { DUP, intron26-intron30 } \\
\text { (842 DEL, } 120 \mathrm{INV}, 417 \mathrm{SI}, 5 \mathrm{TD})\end{array}$ & NA \\
\hline Leber panel & I-II.1 & $1 \mathrm{DEL}$ & (659 DEL, $115 \mathrm{INV}, 339 \mathrm{SI}, 2 \mathrm{TD})$ & NA \\
\hline WES & A-II.1 & 0 & 10 DEL, 3 INV, 10 SI, 1 TD & NA \\
\hline WES & A-II.2 & DUP, intron27-intron30 & $13 \mathrm{DEL}, 3 \mathrm{INV}, 9 \mathrm{SI}$ & NA \\
\hline WGS & A-II.1 & DUP, exon26-intron31 & 14 DEL, 3 INV, 4 SI & 0 \\
\hline WGS & A-II.2 & DUP, exon26-intron31 & $10 \mathrm{DEL}, 2 \mathrm{INV}, 3 \mathrm{SI}$ & 0 \\
\hline WGS & A-I.2 & DUP, exon26-intron31 & $17 \mathrm{DEL}, 1 \mathrm{INV}, 2 \mathrm{SI}$ & 0 \\
\hline WGS & A-I.1 & 0 & $53 \mathrm{DEL}, 1 \mathrm{INV}, 1 \mathrm{SI}$ & 0 \\
\hline
\end{tabular}

Table S7. Summary of the CNV detected in IFT140 by using 3 different tools in 13 individuals.

CNV detection has been performed on 13 individuals sequenced with 4 different approaches: the Ciliome panel, the Leber panel, the WES and the WGS. Three tools have been run with their default options: CANOES (v1.0), Pindel (v0.2.5b9) and CNVnator (v0.3.3) (Abyzov, et al., 2011; Backenroth, et al., 2014; Ye, et al., 2009). The number of CNV detected in IFT140 are reported here, as well as the presence or not of the tandem duplication of exons 26 to 30 . It is to notice that Pindel simultaneously calls small indel and structural variations, increasing thus the number of detected variants. NA, not applicable; DUP, duplication; DEL, deletion; INV, inversion; SI, short insertion; TD, tandem duplication. 


\section{SUPPLEMENTARY REFERENCES}

Abyzov A, Urban AE, Snyder M, Gerstein M. 2011. CNVnator: an approach to discover, genotype, and characterize typical and atypical CNVs from family and population genome sequencing. Genome Res 21(6):974-84.

Adzhubei IA, Schmidt S, Peshkin L, Ramensky VE, Gerasimova A, Bork P, Kondrashov AS, Sunyaev SR. 2010. A method and server for predicting damaging missense mutations. Nature Methods 7(4):248-9.

Backenroth D, Homsy J, Murillo LR, Glessner J, Lin E, Brueckner M, Lifton R, Goldmuntz E, Chung WK, Shen Y. 2014. CANOES: detecting rare copy number variants from whole exome sequencing data. Nucleic Acids Res 42(12):e97.

Bayat A, Kerr B, Douzgou S, Study DDD. 2017. The evolving craniofacial phenotype of a patient with Sensenbrenner syndrome caused by IFT140 compound heterozygous mutations. Clin Dysmorphol 26(4):247-251.

Beheshtian M, Saee Rad S, Babanejad M, Mohseni M, Hashemi H, Eshghabadi A, Hajizadeh F, Akbari MR, Kahrizi K, Riazi Esfahani M and others. 2015. Impact of whole exome sequencing among Iranian patients with autosomal recessive retinitis pigmentosa. Arch Iran Med 18(11):776-85.

Bifari IN, Elkhamary SM, Bolz HJ, Khan AO. 2016. The ophthalmic phenotype of IFT140related ciliopathy ranges from isolated to syndromic congenital retinal dystrophy. $\mathrm{Br} \mathrm{J}$ Ophthalmol 100(6):829-33.

DePristo MA, Banks E, Poplin R, Garimella KV, Maguire JR, Hartl C, Philippakis AA, del Angel G, Rivas MA, Hanna M and others. 2011. A framework for variation discovery and genotyping using next-generation DNA sequencing data. Nat Genet 43(5):491-8.

Gerber S, Alzayady KJ, Burglen L, Bremond-Gignac D, Marchesin V, Roche O, Rio M, Funalot B, Calmon R, Durr A and others. 2016. Recessive and Dominant De Novo ITPR1 Mutations Cause Gillespie Syndrome. Am J Hum Genet 98(5):971-980.

Grampa V, Delous M, Zaidan M, Odye G, Thomas S, Elkhartoufi N, Filhol E, Niel O, Silbermann F, Lebreton C and others. 2016. Novel NEK8 Mutations Cause Severe Syndromic Renal Cystic Dysplasia through YAP Dysregulation. PLoS Genet 12(3):e1005894.

Helm BM, Willer JR, Sadeghpour A, Golzio C, Crouch E, Vergano SS, Katsanis N, Davis EE. 2017. Partial uniparental isodisomy of chromosome 16 unmasks a deleterious biallelic mutation in IFT140 that causes Mainzer-Saldino syndrome. Hum Genomics 11(1):16.

Huerta-Cepas J, Szklarczyk D, Forslund K, Cook H, Heller D, Walter MC, Rattei T, Mende DR, Sunagawa S, Kuhn M and others. 2016. eggNOG 4.5: a hierarchical orthology framework with improved functional annotations for eukaryotic, prokaryotic and viral sequences. Nucleic Acids Res 44(D1):D286-93.

Hull S, Owen N, Islam F, Tracey-White D, Plagnol V, Holder GE, Michaelides M, Carss K, Raymond FL, Rozet JM and others. 2016. Nonsyndromic Retinal Dystrophy due to Bi-Allelic Mutations in the Ciliary Transport Gene IFT140. Invest Ophthalmol Vis Sci 57(3):1053-62.

Khan AO, Bolz HJ, Bergmann C. 2014. Early-onset severe retinal dystrophy as the initial presentation of IFT140-related skeletal ciliopathy. J AAPOS 18(2):203-5.

Kumar P, Henikoff S, Ng PC. 2009. Predicting the effects of coding non-synonymous variants on protein function using the SIFT algorithm. Nature protocols 4(7):1073-81.

Li H, Durbin R. 2010. Fast and accurate long-read alignment with Burrows-Wheeler transform. Bioinformatics 26(5):589-95.

Pena-Padilla C, Marshall CR, Walker S, Scherer SW, Tavares-Macias G, Razo-Jimenez G, Bobadilla-Morales L, Acosta-Fernandez E, Corona-Rivera A, Mendoza-Londono R and others. 2016. Compound heterozygous mutations in the IFT140 gene cause Opitz trigonocephaly $\mathrm{C}$ syndrome in a patient with typical features of a ciliopathy. Clin Genet. 
Perrault I, Saunier S, Hanein S, Filhol E, Bizet AA, Collins F, Salih MA, Gerber S, Delphin N, Bigot K and others. 2012. Mainzer-Saldino syndrome is a ciliopathy caused by IFT140 mutations. Am J Hum Genet 90(5):864-70.

Schmidts M, Frank V, Eisenberger T, Al Turki S, Bizet AA, Antony D, Rix S, Decker C, Bachmann N, Bald M and others. 2013. Combined NGS approaches identify mutations in the intraflagellar transport gene IFT140 in skeletal ciliopathies with early progressive kidney Disease. Hum Mutat 34(5):714-24.

Schwarz JM, Rodelsperger C, Schuelke M, Seelow D. 2010. MutationTaster evaluates disease-causing potential of sequence alterations. Nat Methods 7(8):575-6.

Thorvaldsdottir H, Robinson JT, Mesirov JP. 2013. Integrative Genomics Viewer (IGV): high-performance genomics data visualization and exploration. Brief Bioinform 14(2):178-92. Waterhouse AM, Procter JB, Martin DM, Clamp M, Barton GJ. 2009. Jalview Version 2--a multiple sequence alignment editor and analysis workbench. Bioinformatics 25(9):1189-91.

Weisschuh N, Mayer AK, Strom TM, Kohl S, Glockle N, Schubach M, Andreasson S, Bernd A, Birch DG, Hamel CP and others. 2016. Mutation Detection in Patients with Retinal Dystrophies Using Targeted Next Generation Sequencing. PLoS One 11(1):e0145951.

Xu M, Yang L, Wang F, Li H, Wang X, Wang W, Ge Z, Wang K, Zhao L, Li H and others. 2015. Mutations in human IFT140 cause non-syndromic retinal degeneration. Hum Genet 134(10):1069-78.

Ye K, Schulz MH, Long Q, Apweiler R, Ning Z. 2009. Pindel: a pattern growth approach to detect break points of large deletions and medium sized insertions from paired-end short reads. Bioinformatics 25(21):2865-71. 